DeutscheMedizinischeWochenschrift

inschrift für Schriftleitung und Georg Thieme Verlag: 7000 Stuttgart I, Postfach 732, Herdweg 63

lieirat

W. Bargmann, Kiel

H. E. Bock, Tübingen

A. Butenandt, München

E. Derra, Düsseldorf

G. R. Graham, London
N. Henning, Erlangen

F. Hoff, Frankfurt

H. Leicher, Mainz

E. Letterer, Tübingen

H. Meessen, Düsseldorf
R. Nissen, Basel

K. H. Schäfer, Hamburg

W. Scheid, Köln

G. Schettler, Heidelberg
M. Schneider, Köln

R. Schoen, Göttingen

K. Spang, Stuttgart

A. Windorfer, Erlangen

Schriftleitung: Prof. Dr. F. Grosse-Brockhoff Düsseldorf

Prof. Dr. F. Kümmerle Mainz

Dr. R. H. Rosie Stuttgart

Inhaltsverzeichnis für den 102. Jahrgang

2. Halbjahr 1977 Hefte 27-52

Georg Thieme Verlag · Stuttgart 
Universităts -

Biblióisek

Munctaen

Diejenigen Bezeichnungen, die zugleich eingetragene Warenzeichen sind, wurden nicht besonders kenntlich gemacht. Es kann also aus der Bezeichnung einer Ware mit dem für diese eingetragenen Warenzeichen nicht geschlossen werden, daß die Bezeichnung ein freier Warenname ist. Ebensowenig ist zu entnehmen, ob Patente oder Gebrauchsmuster vorliegen.

Alle Rechte, insbesondere das Recht der Vervielfältigung und Verbreitung sowie der Ubersetzung, vorbehalten. Kein Teil des Werkes darf in irgendeiner Form (durch Photokopie, Mikrofilm oder ein anderes Verfahren) ohne schriftliche Genehmigung des Verlages reproduziert oder unter Verwendung elektronischer Systeme verarbeitet, vervielfältigt oder verbreitet werden.

Some of the product names, patents and registered designs referred to are in fact registered trademarks or proprietary names even though specific reference to this fact is not always made in the text. Therefore, the appearance of a name without designation as proprietary is not to be construed as a representation by the publisher that it is in the public domain.

All rights, including the rights of publication, distribution and sales, as well as the right to translation, are reserved. No part of this work covered by the copyrights hereon may be reproduced or copied in any form or by any means - graphic, electronic or mechanical including photocopying, recording, taping, or information and retrieval systems - without written permission of the publisher.

(c) Georg Thieme Verlag, Stuttgart 1977 - Printed in Germany - Druckhaus Dörr, Inh. Adam Götz, Ludwigsburg 
A

Acetylsalicylsäure, Cholesterinspiegelsenkung 1827

- und Schwangerschaft 1440

- zur Thromboseprophylaxe nach operativem Hüftgelenkersátz 1314

Adenokarzinome des Gastrointestinaltraktes, carcinoembryonales Antigen im Serum 1082

Adenosin-3'5'-monophosphat, zyklisches, Diurese bei Funktionsstörungen der Nebenschilddrüsen 1587

Adipositas, Biotransformation von Hydromorphon 1789

- bei stationären Patienten zwischen 1933 und 1972 1836

Adriamycin, Auslösung einer sekundären kongestiven Kardiomyopathie 1813

-, Kardiotoxizität 1820

- und Bleomycin bei metastasierendem Schilddrüsenkarzinom 1908

Agammaglobulinämie, erworbene, mit vorwiegend intestinaler Symptomatik 1585

,,-- Unverträglichkeit von Gammaglobulin 1822

Agranulozytose bei AprindinBehandlung 1523

- - Behandlung mit Amidonal 1076

-, nach Cotrimoxazol 1287

-, nach Levamisol 1786

Akne, Therapie mit VitaminA-Säure 1743

Akromegalie 1110

Alkohol im Straßenverkehr 1930

Alkoholismus, chronischer, erhöhte Bilirubin- und Kreatinin-Serumwerte 1234

Allergenextrakte, Risiken bei Diagnostik und Therapie 1203

Allergische Erkrankungen, spezifische Hyposensibilisierung 1877

Allopurinol und Libidoverlust 1363

Altersosteoporose; Therapie 1193

Ambulanz, Krankheitsverständnis und PatientenArzt-Beziehung 1239

Amenorrhoe, primäre, und Hypokaliämie infolge $17 \alpha$ Hydroxylase-Mangels 1024

Amidonal, Indikationseinschränkung wegen Agranulozytose-Gefahr 1076
Aminophenazon, Rücknahme der Zulassung als Arzneimittelwirkstoff 1300

-, verlangsamter Umsatz bei akuter Hepatitis im Kindesalter 1460

Aminophyllin, Lungenfunktion und Blutspiegel nach parenteraler Applikation 1916

Aminotransferasen im Serum bei tuberkulostatischer Kombinationstherapie 1913

Amyloidose 1407

-, generalisierte und lokalisierte, Therapie 1593

Anämie, Eisenmangel-, Ferritinkonzentration im Serum 1147

-, -, -Serumferritin zur Kontrolle der oralen Eisentherapie 1150, 1788

-, perniziöse, unbehandelte, HbE-Wert 1864

Aneurysma dissecans aortae, spontane Rückbildung während Hämodialyse 1611

Angina pectoris und Föhn 1106

- -, Prophylaxe mit Molsidomin 1758

Anorexia nervosa und intravasale Gerinnung 1469

Antibiotika, Kombinationsbehandlung 1781

-, bei Salmonellen-Enteritis und asymptomatischer Salmonellose 1720

Antiepileptika, OsteomalazieUrsache bei Erwachsenen, Diagnostik 1872

Antigen, carcinoembryonales, im Serum bei Adenokarzinomen des Gastrointestinaltraktes 1082

,,,--- bei Bronchialkarzinom 1079

,,--- , bei Karzinomen des Gastrointestinaltraktes 1101

Antirefluxplastik bei vesikopyelorenalem Reflux 1929

Anurie bei akuter Linksherzinsuffizienz, Hämofiltration 1804

Aortenbogen, Gewebsstrang im herznahen Anteil 1435

-, Rechtslage 1366

Apoplexie, Risikofaktoren 1437

Aprindin, AgranulozytoseAuslösung 1523

APUD-System, Tagungsbericht 1196

Arbeitsunfähigkeitsbescheinigung, Beweiswert 1230

Artefakt 1441

Arthritis, rheumatoide, $\mathrm{Be}$ handlung mit Sulindac 1772
Arzneimittel, kanzerogene 1047

- Behälter, Sicherheitsverschluß 1172

-, Qualitätsprüfung 1864

- Wechselwirkungen, Frühwarnsystem 1706

Arznei-Sicherheitssystem der Arzte 1784

Arzt-Patienten-Beziehung in Ambulanz 1239

Arztrecht, Aufklärungspflicht 1010

-, Bereitschaftsdienst und Rufbereitschaftsvergütung für angestellte Arzte 1135

-, Beweiswert von Arbeitsunfähigkeitsbescheinigungen 1230

-, Bundesdatenschutzgesetz 1395

-, Haftung des Arztes bei Belastungsuntersuchungen ohne Defibrillationsgerät 1167, 1615

-, KrankenversicherungsKostendämpfungsgesetz 1484

-, neue Parkerleichterung für Arzte im Notfall 1070

-, Neuregelung der Entschädigung für Zeugen und Sachverständige 1739

-, Rechtsstellung von Lernschwestern und Lernpflegern 1328

-, Schweigepflicht zwischen behandelnden Arzten 1785

-, Verweigerung von Praktikumsscheinen wegen Nichtbesuchs begleitender Vorlesungen 1232

Atemwegserkrankungen, obstruktive, Lungenfunktion und Blutspiegel nach parenteraler Euphyllin-Applikation 1916

Aufklärungspflicht, ärztliche 1010

Autopsie in den USA 1204

Azlocillin bei PseudomonasInfektionen 1211

Azotämie und Osmolalität 1894

\section{B}

Basilarisinsuffizienz, Operationsindikation bei einseitiger Vertebralisstenose 1009 , 1200

BCG-Impfung, Lymphadenitis als Nebenwirkung 125

-, Säuglingstuberkulose nach Einstellung der Impfung 1271, 1489, 1823, 1863

Belastungs-EKG bei Digitalisbehandlung 1137, 1399
Belastungshypertonie 1489 Berufskrebse 1015

Bestrahlungsschäden an den Koronarien 1438

Bevölkerungsrückgang 1976 1171

-, abgeschwächt 1866

Biguanide, Lactacidose-Auslösung bei Diabetesbehandlung 1009, 1613, 1863

Bilirubin, Serum-, bei chronischem Alkoholismus 1234

Biperiden bei Schmerzanfällen? 1865

Bleivergiftung durch Kräuterpillen 1898

Bleomycin und Doxorubicin bei metastasierendem Schilddrüsenkarzinom 1908

Blockwirbelbildung, Therapie 1267

Blutbild, Differential-, Färbemethode mit vorgefärbten Objektträgern 1175

Blutdruck, Anstieg bei Belastung 1489

Blutgerinnung, intravasale, bei Anorexia nervosa 1469

Blutsenkungsreaktion, Altersabhängigkeit 1362

Blutung, gastrointestinale, endoskopische Unterspritzung 1688

Bromcarbamid in rezeptfreien

- Schlafmitteln, Vergifturigen 1361

-, Rezeptpflicht 1072, 1140, 1406

Bromcarbamidvergiftungen, endoskopische Entfernung von Tablettenkonglomeraten 1825

Bromhaltige Hypnotika, Diagnostik und Therapie bei Intoxikation 1181

Bromocriptin bei postpartalem Milchstau und puerperaler Mastitis 1754

Bromoderm 1173

Bromureide, Diagnostik und Therapie bei Intoxikation 1181

-, Pharmakokinetik und -dynamik 1530

Bromureid-Vergiftungen, Diagnostik 1641

-, Therapie 1514

Bromvergiftung, Diagnose und Verlaufskontrolle mit Abdomenübersichtsaufnahmen 1824

Bronchialkarzinom, carcinoembryonales Antigen im Serum 1070

-, metastasierendes 1793

Bronchitis, chronische, durch Elektrolytstörungen 1072 
C

Calcitonin, Plasma-, Bedeutung für die klinische Diagnostik 1191

Calcium-Gehalt in Arzneimitteln, Gefahr hypercalcämischer Krisen bei chronischer Niereninsuffizienz 1903

Candida albicans im Stuhl, Therapie 1106

Canrenoat-Kalium, Interferenz mit Digoxinbestimmung im Plasma 1056

Canthaxanthin, kombiniert mit $\beta$-Carotin, bei Lichtdermatosen 1051

Carbamid-Detoxikation durch Gastro- und Duodenotomie 1401

Carbromal-Promethazin-Kombination, Bromismus-Gefahr 1530

Carcinoma in situ, Mamma-, in Fibroadenomen 1495

Carotinoid-Behandlung von Lichtdermatosen 1051

Carotis-Schlaganfall, Stadieneinteilung und chirurgische Therapie 1039

Cephalosporine 1207

China-Restaurant-Krankheit, Häufigkeit 1012

Chlortalidon, Einfluß auf Serum- und GesamtkörperKalium 1838

Cholesterinspiegelsenkung durch Pektine 1235

- durch Salicylate 1827

Cholezystektomie, postoperatives Verhalten der $\gamma$-Glutamyl-Transferase 1897

Chondropathia patellae, Therapie und Prognose 1297

Chorea Huntington, Therapie 1266

Choreomeningitis, lymphozytäre, Úbertragung durch Goldhamster 1367

Chromatinstruktur, neue Befunde 1652

Cimetidin, Auslösung einer cholestatischen Hepatose 1788

- zur Therapie peptischer Ulzera bei Zollinger-EllisonSyndrom 1709

Citrovorum-Faktor-Rescue zur Therapie des Osteosarkoms 1831

Clomethiazol, Indikation und Mißbrauch 1012

Coffeinvergiftung, perkutane 1851

Colitis ulcerosa, Therapie 1067, 1201

Coma diabeticum hyperosmolare, Therapie mit hypertonen Infusionslösungen 1655

- - im Kindes- und Jugendalter, Notfalltherapie 1613

Coma vigile und apallisches Syndrom 1742
Cor pulmonale im Kindesalter infolge chronischer Tonsillenhypertrophie 1120

Corticosteroide, Einfluß auf Tetanus-Antikörperbildung 1929

Cotrimoxazol, Agranulozytose als Nebenwirkung 1287

Cushing-Syndrom und Schwangerschaft 1643

Cyclophosphamid zur Therapie des Osteosarkoms 1831

Cyproteronacetat, Auslösung einer Nebenniereninsuffizienz 1074

-, Induktion von Lebertumoren 1488

Cystinurie, Therapie 1651

D

Darmsarkome, Klinik, Therapie und Prognose 1631

DDAVP bei Hämophilie A und von-Willebrand-JürgensSyndrom 1769

Dermatobia hominis, kutane Myiasis 1385

Dermatochalasis, spätmanifeste 1451

1-Desamino-8-D-Arginin-Vasopressin (DDAVP) zur Behandlung von Hämophilie $\mathbf{A}$ und von-Willebrand-Jürgens-Syndrom 1769

Deutsche Gesellschaft für Nuklearmedizin 1108

Diabetes mellitus, dekompensierter, Behandlung mit automatischem Uberwachungs- und Infusionssystem 1787

_ -, entgleister, Insulinbehandlung mit künstlichem endokrinen Pankreas 1500

- - und familiäre Hypobetalipoproteinämie $\mathbf{1 5 4 9}$

- -, hyperosmolares Koma, Therapie mit hypertonen Infusionslösungen 1655

- -, juveniler, Inselzellantikörper 1221

- -, Lactacidose bei Biguanidbehandlung 1009, 1613, 1863

- -, Myelopathie 1922

- - und Schwangerschaft 1234

- - und terminale Niereninsuffizienz, Hämodialyse 1716

_ -, Vorsicht mit $\beta$-Rezeptorenblockern 1330

Diaethylallylacetamid, Vergiftungen 1591

Dickdarmsarkome, Klinik, Therapie und Prognose 1631

Differentialblutbild, Färbemethode mit vorgefärbten Objektträgern 1175

Diflunisal bei Zerrungen und Verrenkungen 1920

Digitalisbehandlung, Einfluß auf Belastungs-EKG 1137, 1399
Digitalishaftzeichen, diagnostische Bedeutung bei latenter Koronarinsuffizienz 1335, 1698,1892

Digitalisierung, akute, mit $\beta$ Methyldigoxin bei arterieller Hypertonie 989

Digitalisintoxikation bei ambulanter Digoxinbehandlung 1056

Digoxin, Plasma-, bei ambulanter Digitalisbehandlung 1056

Diphtherie, gegenwärtige Situation $\mathbf{1 7 4 7}$

- -Tetanus-Schutzimpfung und Polio-Schluckimpfung gleichzeitig 1168

Diuretika-Abusus, Hypokaliämie mit Polyurie und $\mathrm{Hy}$ perreninismus ohne Aldosteronismus als Leitsymptom 1319

Divertikel, Zenkersches 1568

Dopamin- $\beta$-Hydroxylase im Serum und arterielle Hypertonie 1128

Doxorubicin, Auslösung einer sekundären kongestiven Kardiomyopathie 1813

-, Kardiotoxizität 1820

- zur Therapie des Osteosarkoms 1831

- und Bleomycin bei metastasierendem Schilddrüsenkarzinom 1908

Drogenprobleme, Schriften 1826

Dünndarmsarkome, Klinik, Therapie und Prognose 1631

Dyskeratosis follicularis Darier 1045

Dysplasien, orale 1596

Dystrophia musculorum progressiva Erb, Typ BeckerKiener, mit Myokardbeteiligung 1123

\section{E}

Echinococcus alveolaris 1494

Echinokokkose, Epidemiologie, Diagnostik und Therapie 1098

Echokardiographie, Diagnostik eines Myxoms des linken Vorhofs 997

Eisen, intestinale Absorption 1061, 1699, 1893

Eisenmangelanämie, Ferritinkonzentration im Serum 1147

-, Serumferritin zur Kontrolle der oralen Eisentherapie 1150, 1788

Elektrokardiogramm, Belastungs-, bei Digitalisbehandlung 1137,1399

Elektrolytstörungen bei chronischer Bronchitis 1072

Endoskopie, Notfall-, bei akuter oberer Gastrointestinalblutung 1621, 1927

- zytologische mit farbbeschichteten Objektträgern 1535
Enhancement, immunologisches $\mathbf{1 6 9 0}$

Entrance-Block, kompletter 1746

Enzephalitis, zentraleuropäische, Schutzimpfung 1363

Ergotismus mit funktioneller spastischer Stenose aller Extremitäten-Hauptarterien 1435

Erysipel, rezidivierendes, Therapie 1011

Erythrozyten-Porphyrine, Bestimmung 1882

Euphyllin, Lungenfunktion und Blutspiegel nach parenteraler Applikation 1916

Exit-Block, partieller 1746

Femoralvenenkatheter zur Hämodialyse 1280, 1401

Fernsehen und Gewalt 1364

Ferritin im Serum bei Eisenmangelanämien 1147

_ _ - Kontrollparameter bei oraler Eisentherapie 1150, 1788

Ferroglykokollsulfat, intestinale Fe-Absorption 1061, 1699, 1893

Fetoskopie unter Sichtkontrolle mit Ultraschall $\mathbf{1 3 4 1}$

Fettleberzirrhose, alkoholische 1361, 1614

Fettsucht bei stationären $\mathrm{Pa}$ tienten zwischen 1933 und 19721836

Fibroadenom der Mamma, Exzision 1495

Fibroplasie, retrolentale 1303

Fibrose, retroperitoneale, und Immunkomplex-Glomerulonephritis 1268

-, -, Therapie 1531

Fieber, rheumatisches, Rezidivprophylaxe 1702

Fluorid, Bioverfügbarkeit bei Kombination mit Vitamin $\mathrm{D}_{3} \mathbf{1 6 7 4}$

- -Langzeittherapie der Osteoporose, BeckenkammBiopsien 1177

Fluoride zur Kariesprophylaxe 538,1200

Föhn und Angina-pectorisAnfälle 1106

Folsäure in Plasma und Erythrozyten bei chronischer Niereninsuffizienz 1808

- Mangel 1818

Formaldehyd in Raumluft, Bewertungsmaßstab 1618

_ - -, Reizwirkungen 1612

Furosemid, kardiale und vaskuläre Wirkung 1661

- zur Stimulation des ReninAngiotensin-AldosteronSystems als Suchtest auf Hypertonie 1037 
Galle, Zusammensetzung in ethnischen Gruppen 1108

Gallensteinileus, Diagnostik und Therapie $\mathbf{1 8 8 7}$

Gammaglobulin, Unverträglichkeit bei erworbener Agammaglobulinämie 1822

Gardner-Syndrom 1678

Gastrointestinalblutung, obere akute, Notfallendoskopie 1621, 1927

Geburtenhäufigkeit, regionale Unterschiede 1332

Geburtenrückgang, Ursachen 1204

Geburtenzahl 19761268

Gefäßdarstellung durch transvenöse Xero-Arteriographie 1031

Genitalkarzinome, immunologische Befunde nach Strahlentherapie 1668

Geruch, unverträglicher,

Objektivierung 1169

Geschlechtskrankheiten 1976 1171

Gewebsstrang im Aortenbogen 1435

Gicht, akuter Anfall, Differentialdiagnose 1617

Glibenclamid, Intoxikation 1360

-, Suizidversuch 1070

,-- , Verlauf und Therapie 1524

Glioblastoma multiforme, Therapie 1298

Globulin, thyroxinbindendes, Bestimmung 1386

Glomerulonephritis, Immunkomplex-, bei retroperitonealer Fibrose 1268

-, membranoproliferative 1295

Glossopharyngeus-Neuralgie durch. Neuroleptika? 1790

Glucose, parenteral, bei Mangelernährung, Auslösung von Hypophosphatämie 1422, 1618

$\gamma$-Glutamyl-Transferase nach Cholezystektomie 1897

Glykogenose Typ II (Morbus Pompe) als Myopathie des Erwachsenen 1512

Goldhamster, LCM-Virusverseuchte 1367

Grauwert-Technik zur Verbesserung der Ultraschalldiagnostik 1104

Gummigeruch, Unverträglichkeit 1169

H

Hämodialyse bei Diabetikern mit terminaler Niereninsuffizienz 1716

- bei chronischer Niereninsuffizienz, Folsäure in Plasma und Erythrozyten 1808

- durch perkutane Punktion der V. femoralis 1280, 1401
Hämodialyse, HBs-Antigen bei Dialysepersonal 1826

Hämofiltration bei akuter Linksherzinsuffizienz anurischer Patienten 1804

Hämophilie A, DDAVP-Behandlung 1769

Hämorrhoiden, Pathogenese und Therapie 1244

Hämospermie 1202

Haftpflichtprozesse in den USA 1076

Hamartom der Lunge 1493

Hausbesuche in Amerika 1898

Hauttest, zelluläre Immunreaktivität $\mathbf{1 8 5 2}$

Hepanostika-Test zum Hepatitis-Bs-Antigen-Nachweis 1581

Heparin-Dihydroergotamin zur postoperativen Thromboseprophylaxe, Vergleich mit niedrig dosiertem Heparin 1374

-, niedrig dosiert, zur Thromboseprophylaxe nach operativem Hüftgelenkersatz 1314

Hepatitis, akute, im Kindesalter, Verlangsamung des Aminophenazon-Metabolismus 1460

Hepatitis-Bs-Antigen und AntiHBs bei Krankenhauspersonal 1712

- - bei Dialysepersonal 1826

- - -Nachweis 1267

- - - mit dem HepanostikaTest 1581

Hepatose, cholestatische, nach Cimetidin 1788

Heredopathia atactica polyneuritiformis, Diagnostik und Therapie 1454

- - -, Ubersicht 1480

Herpes gestationis, Therapie und immunpathologische Befunde 1155, 1163

- labialis recidivans, Therapie 1827

Herzinsuffizienz, akute, bei Anurie, Hämofiltration 1804

- , Behandlung mit Vasodilatoren 1388

Herzkrankheit, koronare, Milch als Risikofaktor? 1268,1740

-, -, Wirkung von RetardNitroglycerin auf den Pulmonalarteriendruck 1458

Herzrhythmusstörungen bei chronischem Laxantienabusus 1555

Hiatushernie 1442

Hirndurchblutungsstörungen, Risikofaktoren 1437

Hirnstimulatoren zur Behandlung chronischer Schmerzen 1724

Hiroshima - damals und heute 1111

Histamin- $\mathrm{H}_{2}$-Rezeptor-Antagonisten zur Therapie peptischer Ulzera bei ZollingerEllison-Syndrom 1709
HLA-B8-Antigen bei juvenilem Diabetes mellitus 1221

Hochschulen, Personal 1976/77 1364

Hochwuchs, konstitutioneller, bei Mädchen, Ostrogentherapie 983, 1002

Hodentumoren, maligne, Therapie 1649

Hormonbehandlung in der Schwangerschaft, Schäden bei Kindern 1569

Hüfttotalendoprothese, Altersbegrenzung für die Indikation 1363

Hydrochlorothiazid bei essentieller Hypertonie, allein und kombiniert mit Triamteren 1541

-, Einfluß auf Serum- und Gesamtkörper-Kalium 1838

Hydromorphon, Biotransformation bei Adipositas 1789

Hydrotherapie, immunologische Veränderungen 1625

Hydroxycarbamid beim akuten Blastenschub der chronischmyeloischen Leukämie 1143

$17 \alpha$-Hydroxylase-Mangel, Ursache von primärer Amenorrhoe und Hypokaliämie 1024

Hyperaldosteronismus, primärer, Diagnostik und Therapie 1602

Hypercalcämie durch calciumhaltige Arzneimittel bei chronischer Niereninsuffizienz 1903

Hyperlipidämie-Untersuchungen, Kassenwirtschaftlichkeit 1568

Hyperparathyreoidismus, primärer und sekundärer, cAMP-Diurese 1587

,,-- Diagnostik und Therapie 1602

-, regulativer, Vergleich morphologischer Befunde mit Laboratoriumswerten 1381

Hyperplasie, lymphfollikuläre, im Ileum 1046

Hypersomnie im Kindesalter infolge chronischer Tonsillenhypertrophie 1120

Hypertension, portale, bei kleinknotiger Leberzirrhose infolge Vitamin-A-Vergiftung 1637

Hypertonie, arterielle, Frühdigitalisierung mit $\beta-\mathrm{Me}$ thyldigoxin 989

-, - essentielle, Plasma-Reninund Cortisol-Aktivität bei $\beta$-Rezeptorenblockade 1740

-, -, Behandlung mit Triamteren, Hydrochlorothiazid und Propranolol 1541

-, - maligne, Behandlung mit Minoxidil 1766

-, -, Rehabilitation 1732

,-- , und Serum-Dopamin- $\beta$ Hydroxylase 1128

Hypertonie, arterielle, Suchtest durch Stimulation des ReninAngiotensin-AldosteronSystems mit Furosemid 1037

Hyperthyreose, Therapie 1261

Hyperurikämie, isolierte oder

kombinierte medikamentöse Therapie? 1096

Hypnotika, bromhaltige, Diagnostik und Therapie bei Intoxikation 1181

Hypobetalipoproteinämie, familiäre, und Diabetes mellitus 1549

Hypokaliämie und primäre Amenorrhoe infolge $17 \alpha$ Hydroxylase-Mangels 1024

- bei Pyelonephritis 1702

Hypophosphatämie, Ursache neuromuskulärer Syndrome und respiratorischer Insuffizienz 1422, 1618

Hyposensibilisierung, spezifische, bei allergischen $\mathrm{Er}$ krankungen 1877

Hypothermie 1174

Hypothyreose in der Pubertät, Strumabehandlung mit $\mathrm{T}_{3} / \mathrm{T}_{4}$-Präparaten 1412

\section{I}

Ikterus, Ultraschalluntersuchungen 1559

Immunglobuline, nach Strahlentherapie von Genital- und Mammakarzinomen 1668

Immunkomplexvaskulitis bei Herpes gestationis 1155

Immunmyopathie, neuerkannte 1791

Immunreaktivität, zelluläre, im Hauttest 1852

Impetigo 1533

Induratio penis plastica, Therapie 1651

Infektionskrankheiten 1976 1043

Infertilitätsrisiko bei Varikozele 1651

Influenza-Impfstoffe, Verträglichkeit und Reaktogenität 1370

- -Schutzimpfung, epidemiologische Wirkung 1087, 1399, 1527, 1823

Injektion, intraartikuläre, iatrogene Infektion und Schadenersatz 1168

Inselzellantikörper bei juvenilem Diabetes mellitus 1221

Insuffizienz, respiratorische, bei Hypophosphatämie 1422, 1618

Insulinresistenz 1893

Insult, ischämischer, chirurgische Therapie und Stadieneinteilung 1039

Intoxikation nach Mies: muschelverzehr 1114

Inzest, Vater-Tochter-, zytoge- 
Ionenaustauscher, calciumbeladene, Gefahr hypercalcämischer Krisen bei chronischer Niereninsuffizienz 1903

Isoniacid im Plasma bei tuberkulostatischer Kombinationstherapie 1913

Isosorbiddinitrat, Behandlung der Herzinsuffizienz 1388

\section{$\mathbf{K}$}

Kalium, Serum- und Gesamtkörper-, Einfluß von Chlortalidon, Hydrochlorothiazid und Triamteren 1838

Kaliumhomöostase bei $\mathrm{Ne}$ phropathien 1702

Kaliumsubstitution mit Kochsalzersatzmitteln 1532

Kammerflimmern bei Myokardinfarkt, Warnarrhythmien 1041

Kardiomyopathie nach Adriamycin (Doxorubicin) 1820

-, sekundäre kongestive, nach Adriamycin (Doxorubicin) 1813

Kariesprophylaxe mit Fluoriden 538, 1200

Karzinogene, chemische 1015 - , endogene 1047

Karzinogenese, chemische, im Gastrointestinaltrakt 1516

-, transplazentare 1015

Karzinome des Gastrointestinaltraktes, carcinoembryonales Antigen im Serum 1101, 1082

-, orale 1596

Kehlkopfkarzinom, Therapie 1617

Ketamin, Anwendung 1438

Kiefertumoren, odontogene 1291

Kneipp-Kurbehandlung, immunologische Veränderungen 1625

Knochenhämangiom 1868

Knochentumoren, morphologische Diagnostik 1093

Kochsalzersatzmittel als Kaliumsubstitution 1532

Koma, diabetisches hyperosmolares, Therapie mit hypertonen Infusionslösungen 1655

Kontrazeption, orale, DreiMonats-Behandlung 1891

,,-- Schwangerschaft und Leberkarzinom 1472

Koronararterien, Schädigung durch Bestrahlung parasternaler Lymphknoten 1438

Koronarinsuffizienz, latente, diagnostische Bedeutung der Digitalishaftzeichen 1335, 1698, 1892

-, Nicotinsäuretherapie 1702

-, Wirkung von Molsidomin bei Belastung 1758

Kräuterpillen, Ursache von Bleivergiftung 1898
Krankheiten, meldepflichtige, im dritten Vierteljahr 1977 1743

Krankheitsverständnis in der Ambulanz 1239

Kreatinin, Serum-, bei ambulanter Digitalisbehandlung 1056

-, Serum-, bei chronischem Alkoholismus 1234

Kreatinkinase-BB-Isoenzym, hohe Aktivität als seltene Anomalie 1647

-, MB-Isoenzym-Bestimmung zur Myokardinfarkt-Diagnose 1309, 1701

Krebs-Chemotherapie 1047

- durch Münzen? 1531

Krebstherapie, nichttoxische 1040, 1201

Kreuzotterbiß, Therapie 1138

Kryptokokkenmeningitis 1899

Kurbehandlung, hydrotherapeutische, immunologische Veränderungen 1625

Kurwiederholung erst nach zwei Jahren 1532

L

Laboratoriumstests, Gründe für übermäßige Verordnung 1236

Lactacidose bei Biguanidbehandlung des Diabetes mellitus 1009, 1613, 1863

$\beta$-Lactamring-Antibiotika 1207

Lähmungen bei chronischem Laxantienabusus 1555

- - Hypophosphatämie 1422, 1618

Längenwachstum, übermäßiges, bei Mädchen, Sexualhormontherapie 983, 1002

Lärmschwerhörigkeit, Zunahme 1332

Laparotomie, explorative, bei Lymphogranulomatose 1799

Laxantienabusus, chronischer, extremer Kaliummangel und Folgestörungen 1555

LCM-Virus, Goldhamster als Uberträger 1367

Leberkarzinom, primäres, nach oraler Kontrazeption und Schwangerschaft 1472

Leberkoma, extrakorporale Hämoperfusion mit Pavianlebern 1506, 1862

Lebertumoren nach Cyproteronacetat 1488

Leberzirrhose, kleinknotige, mit portaler Hypertension bei Vitamin-A-Vergiftung 1637

-, portale 1077,1361

Leistenbruch, Implantation von Polyesternetzen 1526

Leukämie, akute myeloische, während Strahlen- und Chemotherapie des M. Hodgkin 1019, 1824

-, chronisch-lymphatische 1829
Leukämie, chronisch-myeloische, Polychemotherapie beim akuten Blastenschub 1143

-, prolymphozytäre, Unterart der chronisch-lymphatischen Leukämie 1443

-, T-Zell-, des Erwachsenen 1848

Leukoplakie, orale 1596

Lichen plano-pilaris 1707

Lichtdermatosen, CarotinoidBehandlung 1051

Lichturticaria, CarotinoidBehandlung 1051

Lidocain, antiarrhythmische Prophylaxe bei Myokardinfarkt 1041

Linksherzinsuffizienz, akute, bei Anurie, Hämofiltration 1804

Linksschenkelblock mit überdrehtem Linkstyp 1896

Liquorzytologie mit vorgefärbten Objektträgern 1216, 1332

Lues II 1109

Lungenfibrose, diffuse 1745

- mit sekundärem Cor pulmonale 1334

Lungenhamartom 1493

Lungenkarzinom und Rauchen 1015

Lungenkrebsdiagnostik 1565

Lungenmykose 1708

Lungenödem, akutes kardiales, Therapie 1256, 1401

- im Kindesalter infolge chronischer Tonsillenhypertrophie 1120

-, Sauerstoffzufuhr 1401

Lungenvolumen 1187

Lymphadenitis, abszedierende, nach BCG-Impfung 1251

Lymphangiosarkom 1698

Lymphfollikuläre Hyperplasie 1046

Lymphogranulomatose, explorative Laparotomie und Splenektomie 1799

Lymphome, Non-Hodgkin-, Differenzierung 1795

-, -, maligne follikuläre, Klinik und Prognose 1273

Lymphozytentransformation, nach Strahlentherapie von Genital- und Mammakarzinomen 1668

\section{M}

Magnesium, Gehalt in Erythrozyten und Plasma im Kindesalter 1065

Mamma-Fibroadenom, Exzision 1495

Mammakarzinom, immunologische Befunde nach Strahlentherapie 1668

- in Fibroadenomen 1495

-, metastasierendes, endokrine und zytostatische Therapie 1477, 1823

-,-, Diagnostik 1475

- und Schilddrüsenhormontherapie 1044

Mammakarzinom-Zellen, Nachweis mit der Immunfluoreszenztechnik 1227

Mangelernährung als Hypophosphatämie-Ursache $\mathbf{1 4 2 2}$ 1618

Manuskripte, Beurteilung für eine allgemeinmedizinische Wochenschrift 1236

Maridi-hämorrhagisches Fieber, neue Viruskrankheit 1575

Marmorknochenkrankheit (Albers-Schönberg) 1574

Masern-Schutzimpfung nach unklarer exanthematischer Erkrankung? 1011

Mastitis, puerperale, Behandlung mit Bromocriptin 1754

Medizin, defensive 1076

Medline 1705

Melanom, metastasierendes 1301

Melanose, prämaligne 1365

Meningosis neoplastica bei malignen Non-HodgkinLymphomen, Prophylaxe 1446

Meralgie, beidseitige, nach Knochenentnahme aus dem Beckenkamm 1928

6-Mercaptopurin beim akuten Blastenschub der chronischmyeloischen Leukämie 1143

Methotrexat zur Therapie des Osteosarkoms 1831

$\beta$-Methyldigoxin bei arterieller Hypertonie und beginnender linksventrikulärer Funktionseinschränkung 989

Metiamid zur Therapie peptischer Ulzera bei ZollingerEllison-Syndrom 1709

Miesmuscheln, Vergiftungen 1114

Milch als Risikofaktor bei koronarer Herzkrankheit? 1268,1740

Milchstau, postpartaler, Behandlung mit Bromocriptin 1754

Minoxidil zur Behandlung der malignen Hypertonie 1766

Mißbildungen durch Hormonbehandlung in der Schwangerschaft 1569

Mitralklappenprolaps mit spätsystolischer Mitralklappeninsuffizienz 1302

Molekularbiologie, angewandte 1572

Molsidomin, Wirkung auf das Belastungs-EKG bei Koronarinsuffizienz 1758

Morbus Boeck, Therapie 1297, 1788

- Cushing, Diagnostik und Therapie 1602

- Darier 1867

- Hodgkin 981

- -, akute myeloische Leukämie nach langjähriger Strahlen- und Chemo- 
Morbus Boeck, explorative Laparotomie und Splenektomie 1799

- Ormond, Therapie 1531

- Pompe als Myopathie des Erwachsenen 1512

Mundschleimhaut, maligne Tumoren 1596

Muskeldystrophie Erb, progressive, Typ Becker-Kiener, mit Myokardbeteiligung 1123

"Muskelkater des Herzens"? 1234

Muskelkrämpfe 1929

Myasthenia gravis, Therapie 1160

Myelom, multiples, Therapie 1289

Myelopathie bei Diabetes mellitus 1922

Myelose, funikuläre 1922

Myiasis, kutane, durch Dermatobia hominis $\mathbf{1 3 8 5}$

Mykose, Lungen- 1708

Mykotoxine, kanzerogene 1015

Myokardinfarkt, akuter, Behandlung mit NitroprussidNatrium 1751

-, antiarrhythmische Prophylaxe mit Lidocain 1041

-, differentialdiagnostische $\mathrm{Be}$ deutung der CK-MB-Bestimmung 1309, 1701

-, nicht-transmuraler, Verteilungsdefekte im myokardialen Perfusionsszintigramm 1347

-, Warnarrhythmien vor Kammerflimmern 1041

Myokardiopathie bei Erbscher Muskeldystrophie, Typ Becker-Kiener 1123

Myopathie beim Erwachsenen bei Typ-II-Glykogenose 1512

- und Hypothyreose durch Diphenylhydantoin 1895

-, Immun-, neuerkannte 1791

Myopie, Erblichkeit 1489

Mytilus edulis, Vergiftungen 1114

Myxom des linken Vorhofs, echokardiographische Diagnose 997, 1647

$\mathbf{N}$

Nachweis von Trichomonas vaginalis 1234

Nebennieren, Indikationskriterien zur radiologischen Darstellung 1614

Nebennierenkrankheiten, Diagnostik und Therapie 1602

Nebennierenrindeninsuffizienz bei Cyproteronacetat-Behandlung 1074

Nebennierentumoren, endokrin-aktive, Lokalisationsdiagnostik 1888

Nebenschilddrüsen-Funktionsstörungen, cAMP-Diurese 1587
Necrobiosis lipoidica 1237

Nephroblastom 1573

Nephrosklerose, maligne, Nierentransplantation 1843

Nervus cutaneus femoris lateralis, doppelseitige Läsion nach Knochenentnahme aus dem Beckenkamm 1928

Neuroleptika, Auslösung einer Glossopharyngeus-Neuralgie? 1790

Niacin bei Koronarinsuffizienz 1702

Nicotinsäure bei Koronarinsuffizienz 1702

Niereninsuffizienz, chronische, Gefahr durch calciumhaltige Arzneimittel 1903

,,-- kompensierte, Folsäure in Plasma und Erythrozyten 1808

-, terminale, und Diabetes mellitus, Hämodialyse 1716

Nierenschäden und Paracetamol? 1011

Nierentransplantation bei maligner Nephrosklerose 1843

Nierentuberkulose, Isolierung 1742

Nierentumoren, maligne, Operationsindikationen 1126

-, -, präoperative Diagnostik 1125

Nierenversagen, chronisches, mathematische Erfassung des Nierenfunktionsverlustes 1038

Nifedipin bei Koronarinsuffizienz 1702

Nitroglycerin, Behandlung der Herzinsuffizienz 1388

-, Retard-, Wirkung auf den Pulmonalarteriendruck bei koronarer Herzkrankheit 1458

Nitroprussid-Natrium, Behandlung der Herzinsuffzienz 1388

- - zur Behandlung des akuten Myokardinfarktes 1751

Nobelpreis 1977 1572, 1741

Non-Hodgkin-Lymphome, Chemotherapie mit modifiziertem MOPP-Schema 1537

- -, Differenzierung 1795

- -, maligne, Diagnostik 1776

,-- , follikuläre, Klinik und Prognose 1273

,-- , im Kindesalter 1567

-, -, Prophylaxe der Meningosis neoplastica 1446

-,-, Therapie 1778

Notfallendoskopie bei akuter oberer Gastrointestinalblutung 1621, 1927

Novonal, Vergiftungen 1591

$\mathbf{O}$

Osophagusdivertikel, Zenkersches 1568
Osophagusvarizenblutung, chirurgische Notfallmaßnahmen 1105

Ostrogen-Gestagen-Therapie bei Mädchen mit konstitutionellem Hochwuchs 983, 1002

Onycholyse bei Hyperthyreose 1619

Operationen, "unnötige «, in den USA 1531

Ormondsche Krankheit,

Therapie 1531

Osmolalität und Azotämie 1894

Osteochondrosis dissecans 1794

Osteopathia antiepileptica, Diagnostik und Therapie 1872

Osteoporose, Alters-, Therapie 1193

-, Beckenkamm-Biopsien bei Fluorid-Langzeittherapie 1177

Osteosarkom, Chemotherapie 1364

-, Polychemotherapie 1831

Ovulationshemmer, Wirkung auf spontane Plättchenaggregation 1248, 1862

Oxyphenbutazon bei Zerrungen und Verrenkungen 1920

Oxyuriasis, Therapie 1168

\section{$\mathbf{P}$}

Pankreaserkrankungen, Ultraschalldiagnostik 1360

Pankreas, künstlicher endokriner, zur Insulinbehandlung des entgleisten Diabetes mellitus 1500

- -Sonographie 1033

Pankreatitis, chronische, Ausschaltung der exokrinen Pankreasfunktion durch komplette Gangligatur 1926

Paracetamol, Ursache von Nierenschäden? 1011

Paraffinfüllung, extrapleurale 982, 1526

Parasitose 1620

Patienten-Arzt-Beziehung in der Ambulanz 1239

Pathologie in den USA

Zukunft 1652

Pavianleber zur extrakorporalen Hämoperfusion bei Leberkoma 1506, 1862

Pektine, Cholesterinspiegelsenkung 1235

Penicillamin, Auslösung von Proteinurie und nephrotischem Syndrom 1035

Penicilline, penicillinase-feste 1207

Perfusionsszintigraphie, myokardiale, diagnostische Bedeutung bei nicht-transmuralem Myokardinfarkt 1347

Perikarditis, beginnende 1238
Perniciosa, unbehandelte $\mathrm{HB}_{\mathrm{E}}$ Wert 1864

Pflegefall, Kriterien 1865

Phäochromozytom, Diagnostik und Therapie 1602

Phentolamin, Behandlung der Herzinsuffizienz 1388

Phlebolithen in der Milz 1142

Phytansäurespeicherkrankheit, Diagnostik und Therapie 1454

-, Úbersicht 1480

Plättchenaggregation, spontane, unter Wirkung von Sexualhormonen 1248, 1862

Plexus chorioideus, verkalkter 1534

Pneumocystis-cariniiPneumonie 1333

Pockenschutzimpfung, orale, Komplikationen 1118

Poliklinik für Berufserkrankungen in Hamburg 1898

-, Krankheitsverständnis und Patienten-Arzt-Beziehung 1239

Poliomyelitis-Schluckimpfung und DT-Impfung gleichzeitig 1168

Polyesternetz, Implantation bei Leisten- und Schenkelbruch 1526

Polyzythämie, relative 1437 , 1740

Porphyrien, erythropoetische, Carotinoid-Behandlung 1051

Porphyrine, Erythrozyten-, Bestimmung 1882

Postmastektomie-Angiosarkom 1141,1400

Präeklampsie, Therapie 1075

Präkordialsyndrom, chondrokostales 1073

Prajmaliumbitartrat in der Schwangerschaft 1330

Prednison beim akuten Blastenschub der chronischmyeloischen Leukämie $\mathbf{1 1 4 3}$

Preise

Dr.-Albert-Wander-Preis 19771898

Anna-Monika-Stiftung 1618

Artur-Pappenheim-Preis 1866

Boehringer-Ingelheim-Preis 1744

Carus-Medaille 1792

Ch.-W.-Hufeland-Medaille 1618

Cothenius-Medaille 1792

E.-K.-Frey-Preis 19771618

Ernst-von-BergmannPlakette 1108

Hans-Huber-Preis 1898

Henry-E.-Sigerist-Preis 1977 1866

Karl-Unholtz-Gedächtnispreis 1744,1898

Leonhart-Fuchs-Medaille 1792

Ludolf-Krehl-Preis 19771618

Ludwig-Heilmeyer-Medaille in Gold 1792

- in Silber 1792 
Ludwig-Rehn-Preis 1744

Ludwig-Schunk-Preis 1866

Mendel-Medaille 1792

Nobelpreis für Medizin 1977 1572, 1741

Paul-Martini-Preis 19771572

Robert-Bing-Preis 19771866

Robert-Feulgen-Preis 1977 1572

Robert-Koch-Medaille 1792

- in Gold 1792

Robert-Koch-Preis 1792

Röntgenpreis 19771898

Schleiden-Medaille 1792

Thannhauser-Preis 1977 1792

Van-Graefe-Preis 1977 1866

Verdienstkreuz am Bande

des Verdienstordens der

Bundesrepublik 1866

Verdienstmedaille 1792

Prindolol und Plasma-Reninaktivität 1740

Propranolol bei essentieller Hypertonie 1541

- und Plasma-Reninaktivität 1740

Prostatakarzinom, Therapie 1423

Proteine, Bedeutung der biologischen Wertigkeit 1431, 1927

Proteinurie infolge Penicillamin 1035

Protoporphyrie, erythropoetische, Carotinoid-Behandlung 1051

Pseudomonas-Infektionen Behandlung mit Azlocillin 1211

Psoriasis 1013

Psychosyndrom, organisches, bei chronischem Laxantienabusus 1555

Pubertätsmagersucht und intravasale Gerinnung 1469

Pulmatosis cystoides coli, Therapie mit Sauerstoffatmung 1869

Punktionszytologie mit farbbeschichteten Objektträgern 1535

Pyelonephritis und Hypokaliämie 1702

Q

Qualitätskontrolle im klinischen Laboratorium 1705

R

Radiojod-Zweiphasentest, heutige Stellung 1001

Radiophosphor, endolymphatische Tumortherapie 1402

Rauchen und Lungenkarzinom 1015

- als Risikofaktor bei Hirndurchblutungsstörungen 1437

Rebound nach Antikoagulantientherapie 1106
Refsum-Syndrom, Diagnostik und Therapie 1454

-, Ubersicht 1480

Rehabilitation bei arterieller Hypertonie 1732

Reklame fürs Krankenhaus 1532

Renin-Angiotensin-AldosteronSystem und $\beta$-Rezeptorenblockade 1740

Rente und Studium 1492

Retikuloid, aktinisches, Carotinoid-Behandlung 1051

$\beta$-Rezeptorenblockade bei essentieller Hypertonie 1740

$\beta$-Rezeptorenblocker, Einfluß auf Kohlenhydratstoffwechsel 1330

Rezidivulkus im operierten Magen, Pathogenese 1730

- - -, präoperative Untersuchungen 1684

Rifampicin im Plasma bei tuberkulostatischer Kombinationstherapie 1913

Robugen-Arzneimittel 50 Jahre 1866

Röteln, Auftreten und Persistenz rötelnspezifischer Antikörper nach Infektion und Schutzimpfung 1418, 1618

Rückenmarkserkrankungen, metabolische, in der zweiten Lebenshälfte 1922

S

Säuglingssterblichkeit, perinatale, in den USA, Ursachen 1492

Säuglingstuberkulose nach Einstellung der BCG-Impfung 1271, 1489, 1823, 1863

Salicylate, Cholesterinspiegelsenkung 1827

Salmonellen-Enteritis und asymptomatische Salmonellosen, Bedeutung der antibiotischen Therapie 1720

Sarkoidose, Therapie 1297, 1788

Sarkome des Dünn- und Dickdarmes, Klinik, Therapie und Prognose 1631

Sauerstoffatmung bei Pneumatosis cystoides coli 1869

Sauerstoffzufuhr bei Lungenödem 1401

Saxitoxin in Miesmuscheln 1114

Schenkelbruch, Implantation von Polyesternetzen 1526

Schenkelhalsbruch, Therapie und Komplikationen 1266

Schilddrüse, Tagungsbericht 1196

Schilddrüsendiagnostik 1296

-, kassenwirtschaftliche 1201

-, rationelle 1136

Schilddrüsenhormon-Therapie und Brustkrebs? 1044
Schilddrüsenhormone, $\mathrm{Be}-$ stimmung 1137

-, Wirkungsweise 1355

Schilddrüsenkarzinom, medulläres, Calcitonin-Plasmakonzentration 1191

-, metastasierendes, Behandlung mit Doxorubicin und Bleomycin 1908

-, papilläres, Therapie 1324, 1649

-, Thyroxinsubstitution nach Operation und Strahlentherapie 1763

Schilddrüsenknoten, "kalter ", Diagnostik 1323

Schilddrüsentumoren, maligne, Diagnostik und Therapie 1602

Schilddrüsenüberfunktion, Therapie 1261

Schlafatmung im Alter 1136

Schlaganfall, Carotis-, Stadieneinteilung und chirurgische Therapie 1039

-, Risikofaktoren 1437

Schlangen, "ungiftige «, $\mathrm{Bi}$ verletzungen 1429

Schlangenbisse, Therapie 1138

Schmerzanfälle, Kupierung mit Biperiden? 1865

Schmerzen, chronische, Behandlung mit Hirnstimulatoren 1724

Schutzimpfung, DT-Impfung und Polio-Schluckimpfung gleichzeitig 1168

-, Influenza-, Verträglichkeit zweier Impfstoffe (Alorbat und Begrivac S) 1370

-, Röteln-, Auftreten und Persistenz rötelnspezifischer Antikörper 1418, 1618

Schwangerschaft, Behandlung der Thrombophlebitis 1228

- und Acetylsalicylsäure 1440

- und Cushing-Syndrom 1643

- und Diabetes mellitus 1234

-, Gefährdung durch Kontakt mit LCM-Virus-verseuchten Goldhamstern 1367

-, Hormonbehandlung und Mißbildungen 1569

- nach oraler Kontrazeption und Leberkarzinom 1472

-, Prajmaliumbitartrat-Medikation 1330

Schwangerschaftsabbruch, Zunahme 1107

Schwangerschaftsabbrüche im zweiten Vierteljahr 1977

1828

Schwindel 1561

Serratia marcescens, Epidemie auf Intensivstation einer Kinderklinik 1350

Sexualhormone, Wirkung auf spontane Plättchenaggregation 1248, 1862

Sexualhormontherapie bei konstitutionellem Hochwuchs junger Mädchen 983, 1002

Sicherheitsverschluß von Arzneimittelbehältern 1172
Sinusbradykardie mit häufigen Knotenersatzschlägen 1014

Skleronychie-Syndrom 1201

Sonographie des Pankreas 1033

Spironolacton, Interferenz mit Digoxinbestimmung im Plasma 1056

Splenektomie bei Lymphogranulomatose 1799

Sputumzytologie mit farbbeschichteten Objektträgern 1535

Stauungsossifikation, chronische venöse 1270

Stenose, spastische, aller Extremitäten-Hauptarterien bei Ergotismus 1435

Sterbefälle.1976 1268

Still-Syndrom, Therapie und Prognose 1330

Straßenverkehrsunfälle im ersten Halbjahr 19771406

Strömungswiderstand in den Atemwegen 1187

Stromausfall und die NewYorker Krankenhäuser 1406

Struma in der Pubertät, »hypothyreote", Behandlung mit $\mathrm{T}_{3} / \mathrm{T}_{4}$-Präparaten 1412

Studentenzahlen im Sommersemester 19771440

Studium und Rente 1492

Subarachnoidalblutung 1830

Sulindac zur Behandlung der rheumatoiden Arthritis 1772

Syndrom, adrenogenitales, Diagnostik und Therapie 1602

-, apallisches, und Coma vigile 1742

-, Conn-, Diagnostik und Therapie 1602

-, Gardner- 1678

-, Hamman-Rich- 1745

-, nephrotisches, infolge Penicillamin 1035

-, Präkordial-, chondrokostales 1073

-, Refsum-, Diagnostik und Therapie 1454

-, -, Ubersicht 1480

-, Still-, Therapie und Prognose 1330

-, von Willebrand-Jürgens, DDAVP-Behandlung 1769

-, Zollinger-Ellison-, Cimetidin-Behandlung peptischer Ulzera 1709

$\mathbf{T}$

Testsimplets zur Erstellung des Differentialblutbildes 1175

- Liquorzytologie 1216, 1332

- zytologische Untersuchung von Punktions- und Endoskopiematerial 1535

Tetanus-Antikörperbildung bei Corticosteroid-Therapie 1929.

Thrombophlebitis in der Schwangerschaft, Therapie 1228 
Thromboseprophylaxe, postoperative, mit Heparin und Acetylsalicylsäure 1314

-, -, und Heparin-Dihydroergotamin 1374

Thrombozytose, idiopathische 1653

Thyroxin zur Substitution bei SchilddrüsenkarzinomPatienten 1763

- bei "hypothyreoter" Struma in der Pubertät statt $\mathrm{T}_{3} / \mathrm{T}_{4^{-}}$ Präparaten 1412

Thyroxinbindendes Globulin, Bestimmung 1386

Todesursachen 19761171

Tonsillenhypertrophie, chronische, Ursache von Cor pulmonale, Lungenödem und Hypersomnie im Kindesalter 1120

Toxikologie in der Krebsforschung 1015, 1047

Transaminasen im Serum bei tuberkulostatischer Kombinationstherapie 1913

Tretionin zur Akne-Therapie 1743

Triamteren, antikaliuretische Wirkung bei Kombination mit Chlortalidon 1838

- -Hydrochlorothiazid bei essentieller Hypertonie 1541

Trichomonas vaginalis, Nachweis 1234

Trijodthyronin-Hyperthyreose bei Behandlung jugendlicher Struma-Patienten mit $T_{3} / T_{4}$ Präparaten 1412

Tuberkulose, Epidemiologie bei Säuglingen nach Aussetzen der BCG-Impfung 1271, 1489, 1823, 1863

-, Lungen-, Rifampicin- und Isoniazid-Plasmaspiegel und Aminotransferasen im Serum bei tuberkulostatischer Kombinationstherapie 1913

-, Urogenital-, Isolierung 1742

Tuberkulostatika, teratogene Wirkung 1075
Tumoren, maligne, endolymphatische RadionuklidTherapie 1402

Turmschädel 1206

\section{U}

Ubergewicht als Risikofaktor bei Hirndurchblutungsstörungen 1437

Ulcus duodeni, operative Behandlung, Umfrage-Ergebnis 1409

- pepticum, Rezidiy im operierten Magen, Pathogenese 1730

- - bei Zollinger-Ellison-Syndrom, Cimetidin-Behandlung 1709

Ulkus, Rezidiv-, im operierten Magen, präoperative Untersuchungen $\mathbf{1 6 8 4}$

Ultraschalldiagnostik bei

Pankreaserkrankungen 1360

-, verbesserte, durch Grauwertdarstellung 1104

Ultraschalltomographie des Pankreas 1033

Ultraschalluntersuchungen bei Ikterus 1559

Unterspritzung, endoskopische, bei gastrointestinalen Blutungen 1688

Urogenitaltuberkulose, Isolierung 1742

Urolithiasis, Therapie 1353

\section{V}

Varikozele, Infertilitätsrisiko 1651

Varizellen, wechselseitige Kontagiosität mit Zoster 1402

Vasektomie, immunologische Aspekte 1853

Vasodilatoren, Behandlung der Herzinsuffizienz 1388

Vaterschaftsnachweis, zytogenetischer, bei Vater-TochterInzest 999
Vena femoralis, perkutane Punktion zur Hämodialyse 1280, 1401

Vergiftung, Coffein-, perkutane 1851

-, Glibenclamid- 1070

- nach Miesmuschelverzehr 1114

Vergiftungen, Brom-, Diagnose und Verlaufskontrolle mit Abdomenübersichtsaufnahmen 1824

-, Bromcarbamid-, endoskopische Entfernung von Tablettenkonglomeraten 1825

-, Bromureid-, Diagnostik 1641

-, -, Therapie 1514

-, Carbamid-, Detoxikation durch Gastro- und Duodenotomie 1401

-, Vitamin-A-, nach Psoriasisbehandlung, Leberzirrhose infolge $\mathbf{1 6 3 7}$

Verrenkungen, Behandlung mit Diflunisal und Oxyphenbutazon 1920

Verrucae juveniles, Therapie 1789

Vertebralisstenose, einseitige, Operationsindikation 1009 1200

Vesikopyelorenaler Reflux, Antirefluxplastik 1929

Vincristin beim akuten Blastenschub der chronischmyeloischen Leukämie $\mathbf{1 1 4 3}$

- oder Vinblastin? 1790

Virus der lymphozytären Choriomeningitis, Goldhamster als Infektionsquelle $\mathbf{1 3 6 7}$

Viruskrankheit, neue, Maridihämorrhagisches Fieber 1575

Vitamin-A-Säure zur AkneTherapie 1743

- -Vergiftung nach Psoriasisbehandlung, Leberzirrhose infolge 1637

- $-\mathrm{B}_{12}$-Mangel, Myelopathie 1922

- - im Plasma bei chronischer Niereninsuffizienz 1808
Vitamin $\mathrm{D}_{3}$, Bioverfügbarkeit von Fluorid bei kombinierter Gabe 1674

- D bei Osteopathia antiepileptica 1872

Vorderwandinfarkt mit Hinterwandschwiele 1654

Vorhof-Extrasystolen, nicht übergeleitete 1408

Vorhofseptumdefekt vom Secundum-Typ mit verlängertem AV-Intervall 1552

Vorhoftachykardie, paroxysmale 1078

\section{W}

Warnarrhythmien vor Kammerflimmern bei Myokardinfarkt 1041

Warzen, juvenile, Therapie 1789

Wertigkeit, biologische, von Proteinen 1431, 1927

von Willebrand-Jürgens-Syndrom, DDAVP-Behandlung 1769

$\mathbf{X}$

Xero-Arteriographie, transvenöse, der Extremitäten 1031

\section{Z}

Zenkersches Divertikel 1568

Zerrungen, Behandlung mit Diflunisal und Oxyphenbutazon 1920

Zollinger-Ellison-Syndrom, Cimetidin-Behandlung peptischer Ulzera 1709

Zoster, wechselseitige Kontagiosität mit Varizellen 1402

Zytomegalie 1205, 1269

- -Virusinfektion, Diagnose 1009

Zytostatika-Installation nach Abpunktion maligner Ergüsse 1617

\section{Buchbesprechungen}

Antonaccio, M. J.: Cardiovascular Pharmacology. (Greeff, K.) 1491

Bargmann, W.: Histologie und Mikroskopische Anatomie des Menschen. (Holstein, A. F.) 1490

Becker, P. E. (Hrsg.): Humangenetik. Ein kurzes Handbuch in fünf Bänden. Band
III/3: Hämatologie. (Fuhrmann, W.) 1170

Bernbeck, R., G. Dahmen:

Kinderorthopädie. (Parsch, K.-D.) 1404

Bräutigam, W.: Sexualmedizin im Grundriß. Eine Einführung in Klinik, Theorie und Therapie der sexuellen Konflikte und Störungen. (Thomas, K.) 1202
Burge, H., E. H. Farthmann, G. Grassi, St. B. Hedenstedt, L. F. Hollender, $H$. W. Schreiber, N. C. Tanner (Hrsg.): Vagotomie. Indikationen - Taktik - Technik, Komplikationen, Ergebnisse, Kommentare. (Largiadèr, F.) 1169

Curran, R. C., E. L. Jones: Farbatlas der makroskopi- schen Pathologie. (Cain, H.) 1139

Doerr, W., G. Seifert, E. Uehlinger (Hrsg.): Spezielle pathologische Anatomie. Ein Lehr- und Nachschlagewerk. Band 2, Teil 2: Darm und Peritoneum. (Elster, K.) 1299

Early Care of the Injured Patient. By the Committee on Trauma, American Col- 
lege of Surgeons. (Wannske, M.) 1405

Eckert, P.: Das Niederdrucksystem. Grundlagen und Klinik. (Scheppokat, K.-D.) 1331

Ewerbeck, H.: Differentialdiagnose von Krankheiten im Kindesalter. Ein Leitfaden für Klinik und Praxis. (Helwig, H.) 1331

Fischer, J. T.: Zur Bedeutung des Komplementsystems bei immunhämolytischen Anämien. (Fischer, K.) 1570

Fischer, W. M. (Hrsg.): Kardiotokographie. Lehrbuch und Atlas. (Kubli, F.) 1703

Geldmacher von Mallinckrodt, M.: Einfache Untersuchungen auf Gifte im klinischchemischen Laboratorium. (Pribilla, O.) 1138

Gremmel, H., H.-A. Ladner, O. Messerschmidt, G. Möhrle, F.-E. Stieve, R. Zimmer (Hrsg.): Risiko der Gefährdung durch die Strahlenexposition in der Medizin. Strahlenschutz bei der Luftund Raumfahrt. (Frik, W.) 1570

Gries, F. A., P. Berchtold, M. Berger: Adipositas. Pathophysiologie, Klinik und Therapie. (Liebermeister, H.) 1203

Hamashima, Y.: Immunohistopathology. (Wick, G.) 1139

Handbuch der medizinischen Radiologie. Band V/Teil 1: Röntgendiagnostik der Skeletterkrankungen. (Brocher, J. E. W.) 1791
Heinrich, K.: Psychopharmaka in Klinik und Praxis. (Kielholz, P.) 1404

Holm, H. H., J. K. Kristensen, S. N. Rasmussen, J. F. Pedersen, S. Hancke: Abdominal Ultrasound. (Rettenmaier, G.) 1704

Holzhauser, K. P., K.-H. Schaller: Arbeitsmedizinische Untersuchungen bei Schornsteinfegern. Gefährdung am Arbeitsplatz und berufsbedingte Gesundheitsschäden. (Ulmer, W. T.) 1790

Hope-Stone, H. F.: Radiotherapy in Modern Clinical Practice. (Scherer, E.) 1203

Jadassobn, J.: Handbuch der Haut- und Geschlechtskrankheiten. Ergänzungswerk, 3. Band/3. Teil A: Nicht entzündliche Dermatosen. III. Gut- und bösartige Neubildungen der Haut. Sklerosen. (Steigleder, G. K.) 1404

Jaeger, W.: Die Heilung des Blinden in der Kunst. (Schipperges, H.) 1571

James, J.: Light Microscopic Techniques in Biology and Medicine. (Haselmann, $\mathrm{H}$.) 1439

Kirkpatrick, Ch. H., H. Y. Reynolds: Immunologic and Infectious Reactions in the Lung. (Medici, T. C.) 1299

Kratochwil, A.: Ultraschalldiagnostik in der Inneren Medizin, Chirurgie und Urologie. Atlas und Lehrbuch. (Koischwitz, D.) 1438
Mathé, G.: Immunthérapie Active des Cancers. Immunoprévention - Immunorestauration. (Nagel, G.) 1139

Meyer, J. S., H. Lechner, M. Reivich (Ed.): Cerebral Vascular Disease. (Dorndorf, W.) 1299

Nöcker, J.: Physiologie der Leibesübungen für Sportlehrer, Trainer, Sportstudenten, Sportärzte. (Böning, D.) 1404

Nord, D.: Arzneimittelkonsum in der Bundesrepublik Deutschland. Eine Verhaltensanalyse von PharmaIndustrie, Arzt und Verbraucher. (Gross, F.) 1439

Paoletti, R., A. M. Gotto, Jr (Ed.): Atherosclerosis Reviews. (Augustin, J. und Klose, G.) 1704

Robbins, J. B., V. T. De Vita, W. Dutz: Symposium on Pneumocystis carinii Infection. (Müller, R. W.) 1170

Rosin, H.: Antibiotika und Meningitis purulenta. Klinisch-pharmakologische Studien zur Liquorgängigkeit von Gentamycin und Ticarcillin bei experimenteller Meningitis. (Kienitz, M.) 1331

Schäcke, G.: Herzschlagfrequenz und Elektrokardiogramm in der Arbeitsmedizin. Radiometrische Untersuchungen. (Samek, L.) 1169

Schreck, E.: Differentialdiagnose in der Ophthalmologie. (Heilmann, K.) 1705
Spaar, F.-W.: Die menschliche Herpes-simplex-Encephalitis und -Meningitis. Eine klinisch-neuropathologische Untersuchung. (Ackermann, R.) 1571

Staebelin, B.: Der finale Mensch. Therapie für Materialisten. (Jenny, S.) 1405

Stockamp, K.: Alpha-Rezeptorenblocker und Harnblasendysfunktion. (May, P.) 1170

Szent-Györgyi, A.: Electronic Biology and Cancer. (Kinzel, V.) 1491

Talbott, J. H., T.-F. Yü: Gout and Uric Acid Metabolism. With a Chapter on Intermediary Purine Metabolism by J. E. Seegmiller. (Wolfram, G.) 1491

Thurn, P., E. Bücheler: Einführung in die Röntgendiagnostik. (Anacker, H.) 1704

Valentin, H., K. P. Holzhauser: Funktionsprüfungen von Herz und Kreislauf. (Petersen, P.) 1791

Wiedemann, H.-R., F.-R. Grosse, H. Dibbern: Das charakteristische Syndrom. Blickdiagnose von Syndromen. Ein Atlas für Klinik und Praxis. (Helwig, H.) 1571

Yoshii, Z., J. Tokunaga, J. Tawara (Ed.): Atlas of Scanning Electron Microscopy in Microbiology. (Lickfeld, K.) 1298

\section{Verhandlungsberichte}

Endokrinologisch-chirurgisches Symposium, Bericht über ein interdisziplinäres Treffen an der Chirurgischen Universitätsklinik Mainz am 3. und 4. Juni 19771602
Maligne Non-Hodgkin-Lymphome des Kindesalters. Sektion Paidopathologie der Deutschen Gesellschaft für Pathologie, 16. April 1977 in Erlangen. 1567
Peripheres disseminiertes endokrines Zellsystem (APUD-System) und Schilddrüse. Sektion Gynäkopathologie der Deutschen Gesellschaft für Pathologie, 12.-16. April 1977 in Erlangen 1196 


\title{
Diagnostik der Osteopathia antiepileptica im Erwachsenenalter
}

\author{
K.-H. Krause, P. Prager, H. Schmidt-Gayk und E. Ritz
}

Neurologische Universitätsklinik (Direktor: Prof. Dr. H. Gänshirt), Universitäts-Strahlenklinik

(Direktor: Prof. Dr. K. zum Winkel) und Medizinische Universitätsklinik (Direktor: Prof. Dr. G. Schettler), Heidelberg

Bei 100 Anfallskranken, die unter einer antiepileptischen Langzeitbehandlung standen, wurden zur Aufdeckung einer medikamentös bedingten Osteopathie Röntgenaufnahmen der Hände und Füße angefertigt sowie 25-Hydroxycholecalciferol, Parathormon, alkalische Phosphatase, Calcium und anorganisches Phosphat im Serum bestimmt. Die Korrelation der einzelnen Parameter wurde überprüft. Als besonders wertvoll zur Früherkennung osteomalazischer Prozesse erwiesen sich dabei die Bestimmungen des 25-Hydroxycholecalciferols sowie die Röntgenuntersuchung des Skeletts. Deshalb wird empfohlen, in Zukunft eines dieser beiden Verfahren neben den Routinebestimmungen im Serum bei jährlichen Kontrolluntersuchungen erwachsener Epileptiker einzusetzen, damit frühzeitig eine adäquate Therapie mit Vitamin-D-Präparaten erfolgen kann.

Nach der Erstbeschreibung der bei Langzeitmedikation von Antiepileptika auftretenden Osteopathie 1967/68 bei Kindern $(13,19)$ wurde seit 1970 mehrfach über entsprechende Knochenveränderungen auch bei Erwachsenen berichtet $(2,7,10,21,22)$. Bei den zur Aufdeckung von Osteomalazien durchgeführten Reihenuntersuchungen an erwachsenen Epileptikern wurden als diagnostische Verfahren Messungen der alkalischen Phosphatase und des Serumcalciums $(4,7,8,11,12,15-18,20)$, der Calciumresorption $(12,18)$, des anorganischen Phosphats (16) und des 25-Hydroxycholecalciferols im Serum $(11,21)$ sowie Bestimmungen der Knochendichte auf Röntgenaúfnahmen $(8,20)$ oder mittels Photonenabsorptionsmessungen $(4,15)$ angewendet. Zur Beurteilung des Stellenwertes der einzelnen Untersuchungsmethoden erscheint es angebracht, systematisch röntgenologische Befunde am Skelettsystem mit allen serologischen Parametern einschließlich 25-Hydroxychole-
Diagnosis of anticonvulsant osteomalacia in adults

In 100 epileptic patients under treatment with long-term anticonvulsants, radiographs of the hands and feet, and estimations of serum 25-hydroxycholecalciferol, parathormone, alkaline phosphatase, calcium, and inorganic phosphate were done to detect a medication-induced osteomalacia. The correlation between the individual parameters was investigated. It was shown that the serum 25 -hydroxycholecalciferol level and the skeletal radiograph were the most valuable in the early detection of osteomalacia. One of these investigations in addition to routine serum chemistry is recommended for the future at the yearly follow-up examinations of adult epileptics so that early and adequate treatment with vitamin $\mathrm{D}$ can be started. calciferol und Parathormon zu vergleichen. Im folgenden soll erstmals über eine entsprechende Reihenuntersuchung an erwachsenen Patienten berichtet werden.

\section{Patienten und Methoden}

100 Patienten (68 männlich, 32 weiblich) der Anfallsambulanz der Neurologischen Universitätsklinik Heidelberg wurden im Rahmen der routinemäßigen Uberwachung untersucht. Das Alter lag zwischen 16 und 72 Jahren, das Durchschnittsalter bei 40,2 Jahren. Die Dauer der antiepileptischen Medikation betrug 1-24, durchschnittlich 10,6 Jahre. Bei 23 Patienten wurden zum Zeitpunkt der Untersuchung ausschließlich Hydantoinpräparate, meist in einer Dosierung von $200-400 \mathrm{mg} / \mathrm{d}$ gegeben, in den übrigen Fällen Kombinationen von Hydantoinen und anderen Antiepileptika, vorzugsweise Primidon, aber auch Carbamazepin, Barbiturat und Dipropylacetat.

Bei allen Patienten wurden Röntgenaufnahmen des Hand- und Fußskelettes, bei den meisten zusätzlich auch Aufnahmen des Bekkens und der Lendenwirbelsäule, außerdem gezielt - je nach Klinik anderer Skelettabschnitte wie Brust- und Halswirbelsäule oder 
Tibia angefertigt. Die Hände wurden mit einem Mammographiegerät bei $30 \mathrm{kV}$ Spannung und Belichtungsautomatik geröntgt. Die Auswertung erfolgte mit einer Handlupe (Leitz, Wetzlar, $8 \times$ ). Zugrunde gelegt wurden die Erfahrungen, die an über 100 skelettgesunden erwachsenen Probanden gewonnen wurden. Bei der Befundung wurden durch verschiedene Beobachter ohne Kenntnis der chemischen Werte drei Stufen unterschieden. Der Gruppe 1 gehörten Patienten mit normalem Befund an, in die Gruppe 2 wurden Patienten mit einem verdächtigen oder fraglich positiven Befund (zum Beispiel ungewöhnliche Corticalis-Verschmälerung, Porosierung, pathologischer Garn-Index [9]) eingeordnet. Eindeutig krankhafte Befunde (pathologische Frakturen, Loosersche Umbauzonen, subperiostale Resorptionen, ausgeprägte Skelettrarefizierung) wurden der Gruppe 3 vorbehalten.

Im Serum wurden die Werte für alkalische Phosphatase, anorganisches Phosphat und Calcium bestimmt (Technicon AutoAnalyzer SMA 12/60). Der Serumspiegel des 25-Hydroxycholecalciferols wurde im kompetitiven Proteinbindungsassay nach Edelstein und Mitarbeitern (6), der des Parathormons im Radioimmunassay nach Arnaud und Mitarbeitern (1) mit dem Antiserum 211/32 von Burroughs-Wellcome gemessen.

Die Beziehungen zwischen Röntgenbefunden und den Parametern im Serum wurden statistisch mit dem H-Test nach Kruskal und Wallis überprüft, die Korrelation zwischen 25 -Hydroxycholecalciferol- und Parathormon-Spiegel sowie den übrigen Serumwerten mit dem Verfahren der linearen Regression.

\section{Ergebnisse}

Der Röntgenbefund zeigte in 34 Fällen einen Verdacht oder fraglich positiven Befund (Stufe 2), in fünf Fällen bestanden deutliche Hinweise auf Osteopathie (Stufe 3). In zweien dieser Fälle wurde eine Beckenkammbiopsie durchgeführt, die den Röntgenbefund bestätigte. Eine Erniedrigung des 25-Hydroxycholecalciferol-Spiegels auf $25 \mathrm{nmol} / \mathrm{l}$ (untere Grenze bei einer Kontrollgruppe von zehn gesunden Erwachsenen im Alter von 20-40 Jahren) und darunter fand sich $23 \mathrm{mal} ; 26 \mathrm{mal}$ wurde eine Erhöhung des Parathormon-Spiegels auf über $40 \mathrm{pmol} / 1$ (Normalbereich in einer Gruppe von 50 gesunden Erwachsenen: $10-40 \mathrm{pmol} / \mathrm{l}$ ) nachgewiesen. Die Werte der alkalischen Phosphatase lagen zwanzigmal bei $120 \mathrm{U} / 1$ und darüber (Normalbereich bei einer gesunden Vergleichsgruppe von 30 Erwachsenen über 18 Jahre 40 bis 120 U/l). Der Calciumspiegel betrug in 24 Fällen weniger als $2,25 \mathrm{mmol} / \mathrm{l}$, das anorganische Phosphat war siebzehnmal unter $0,81 \mathrm{mmol} / 1(25 \mathrm{mg} / \mathrm{l})$ erniedrigt, das Calcium-Phosphat-Produkt $(g / 1 \times g / l)$ einundzwanzigmal auf Werte unter 0,0025 .

Tab. 1. Häufigkeit von Kombinationen pathologischer Untersuchungsbefunde bei gleichen Probanden

\begin{tabular}{|c|c|c|c|c|c|c|c|c|c|}
\hline & 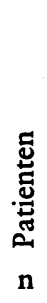 & 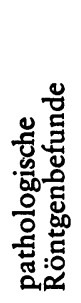 & 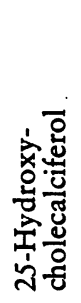 & 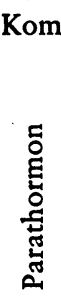 & 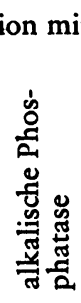 & $\frac{E}{\frac{E}{J}}$ & 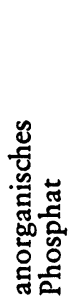 & 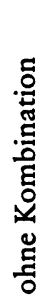 & 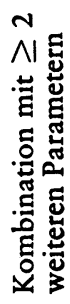 \\
\hline 25-Hydroxycholecalciferol & 23 & 18 & - & 10 & 10 & 8 & 3 & 2 & 16 \\
\hline Parathormon & 26 & 14 & 10 & - & 5 & 6 & 5 & 5 & 13 \\
\hline alkalische Phosphatase & 20 & 11 & 10 & 5 & - & 6 & 4 & 3 & 11 \\
\hline Calcium & 24 & 13 & 8 & 6 & 6 & - & 2 & 6 & 11 \\
\hline anorganisches Phosphat & 17 & 6 & 3 & 5 & 4 & 2 & - & 6 & 9 \\
\hline
\end{tabular}

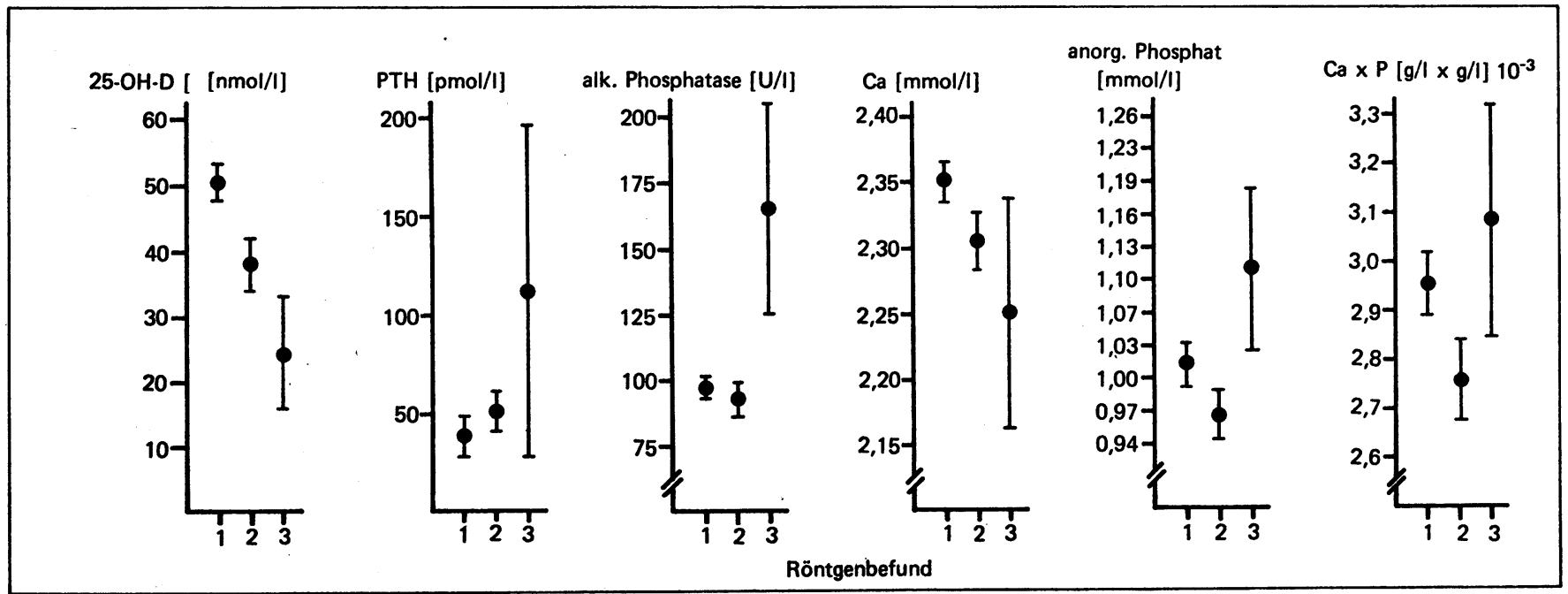

Abb. 1. Beziehung zwischen Röntgenbefund uñd Serumwerten $(\bar{x} \pm s)$. Röntgenbefund: $1=$ normal $(n=61$ ), $2=$ verdächtig ( $n=34$ ), $3=$ eindeutig pathologisch $(n=5) .25-\mathrm{OH}-\mathrm{D}=25-\mathrm{Hydroxycholecalciferol,} \mathrm{PTH}=$ Parathormon. 
Die Häufigkeit von Kombinationen der einzelnen Serumwerte untereinander ist Tabelle $1 \mathrm{zu}$ entnehmen. Danach waren alle Parameter am häufigsten mit pathologischen Röntgenbefunden kombiniert. Bei einem Vergleich der Häufigkeit von Kombinationen von mehreren weiteren pathologischen Befunden beim gleichen Patienten erwies sich das 25-Hydroxycholecalciferol als der verläßlichste Parameter; hier wurden bei 16 von $23 \mathrm{~Pa}$ tienten die erniedrigten 25 -Hydroxycholecalciferol-Spiegel ergänzt durch mindestens zwei weitere pathologische Untersuchungsergebnisse.

Die Röntgenbefunde wurden gesondert gegen die aus dem Serum gewonnenen Werte aufgetragen (Abbildung 1). Hier zeigte sich vor allem eine ausgezeichnete Korrelation zum 25-Hydroxycholecalciferol-Spiegel, der sich bei Röntgenstufe 2 und 3 jeweils signifikant erniedrigte $(P<0,01)$; eine geringere, statistisch jedoch noch gesicherte Beziehung bestand zu alkalischer Phosphatase und Calcium $(P<0,05)$. Eine eindeutige Korrelation mit Parathormon, anorganischem Phosphat und Ca-P-Produkt ließ sich statistisch nicht nachweisen. Bei einem Ver-

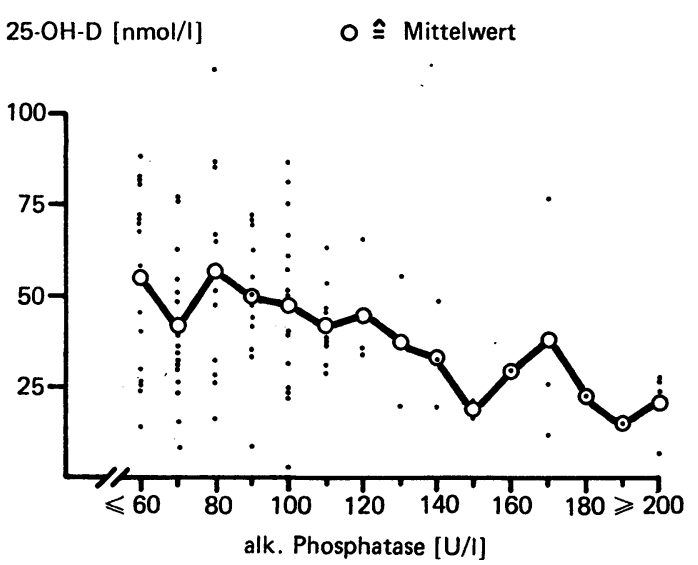

Abb. 2. Beziehung zwischen den Serumspiegeln von alkalischer Phosphatase und 25-Hydroxycholecalciferol (25-OH-D). '

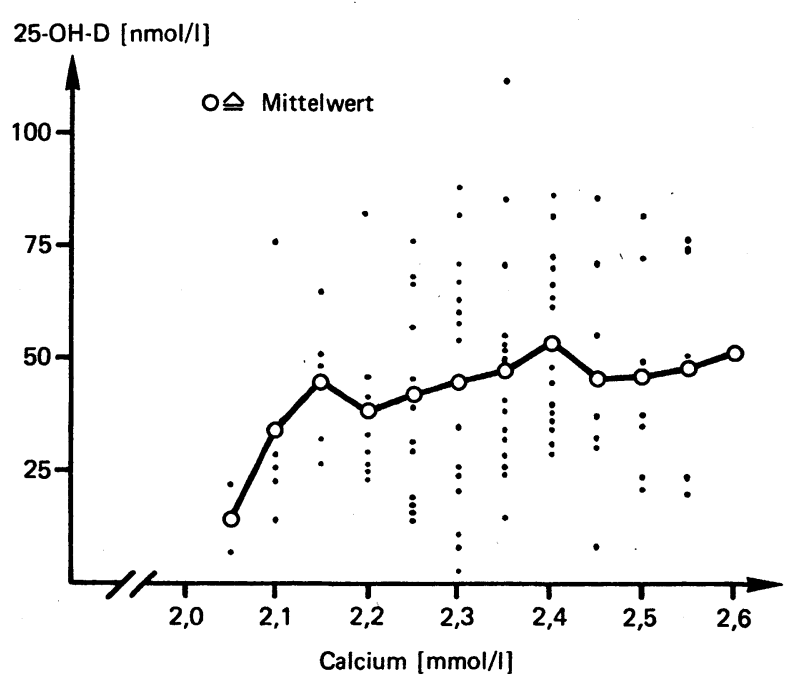

Abb. 3. Beziehung zwischen den Serumspiegeln von Calcium und 25-Hydroxycholecalciferol (25-OH-D). gleich der Ergebnisse der 25-Hydroxycholecalciferol-Bestimmung mit den Werten der alkalischen Phosphatase, des Calciums, des anorganischen Phosphats sowie des Ca-P-Produktes (Abbildung 2-5) ergab sich eine recht gute Übereinstimmung mit den beiden erstgenannten Parametern $(P<0,01$ für alkalische Phosphatase, $P<0,1$ für Ca). Eine Korrelation mit anorganischem Phosphat und Calcium-Phosphat-Produkt ließ sich dagegen nicht sichern.

Bei der Úberprüfung der Beziehung zwischen Parathormon-Wert und den übrigen Parametern im Serum mit dem Verfahren der Regression ergab sich lediglich für die alkalische Phosphatase eine gesicherte Korrelation $(P<0,05)$. Die mangelhafte Úbereinstimmung erhöhter Parathormon-Werte zwischen 40 und' 100 pmol/1 mit pathologisch veränderten anderen Serumwerten ist aus Abbildung $6 \mathrm{zu}$ ersehen; erst bei deutlich erhöhtem Parathormon-Spiegel über $100 \mathrm{pmol} / 1$ lagen auch die übrigen Parameter häufiger im pathologischen Bereich.

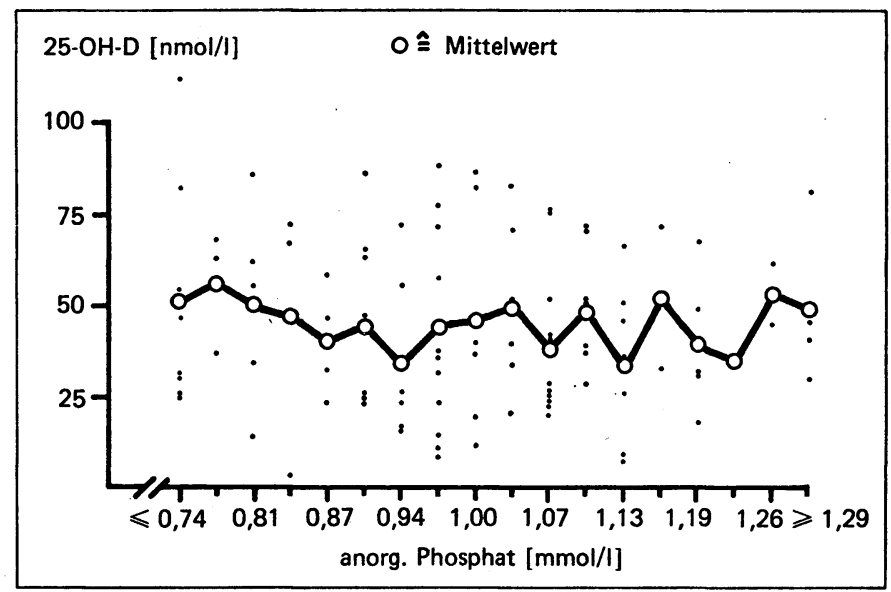

Abb. 4. Beziehung zwischen den Serumspiegeln von anorganischem Phosphat und 25-Hydroxycholecalciferol (25-OH-D).

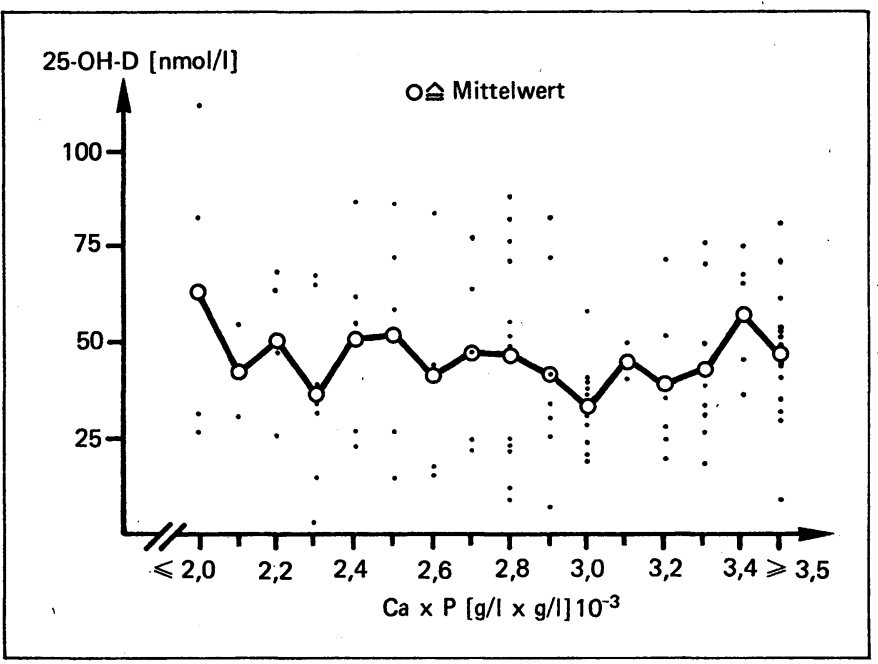

Abb. 5. Beziehung zwischen Calcium-Phosphat-Produkt und 25Hydroxycholecalciferol (25-OH-D) im Serum.

\section{Diskussion}

25-Hydroxycholecalciferol. Störungen im Vitamin-DStoffwechsel werden als wesentlicher ätiologischer Faktor für die Entstehung der Osteopathia antiepileptica an- 


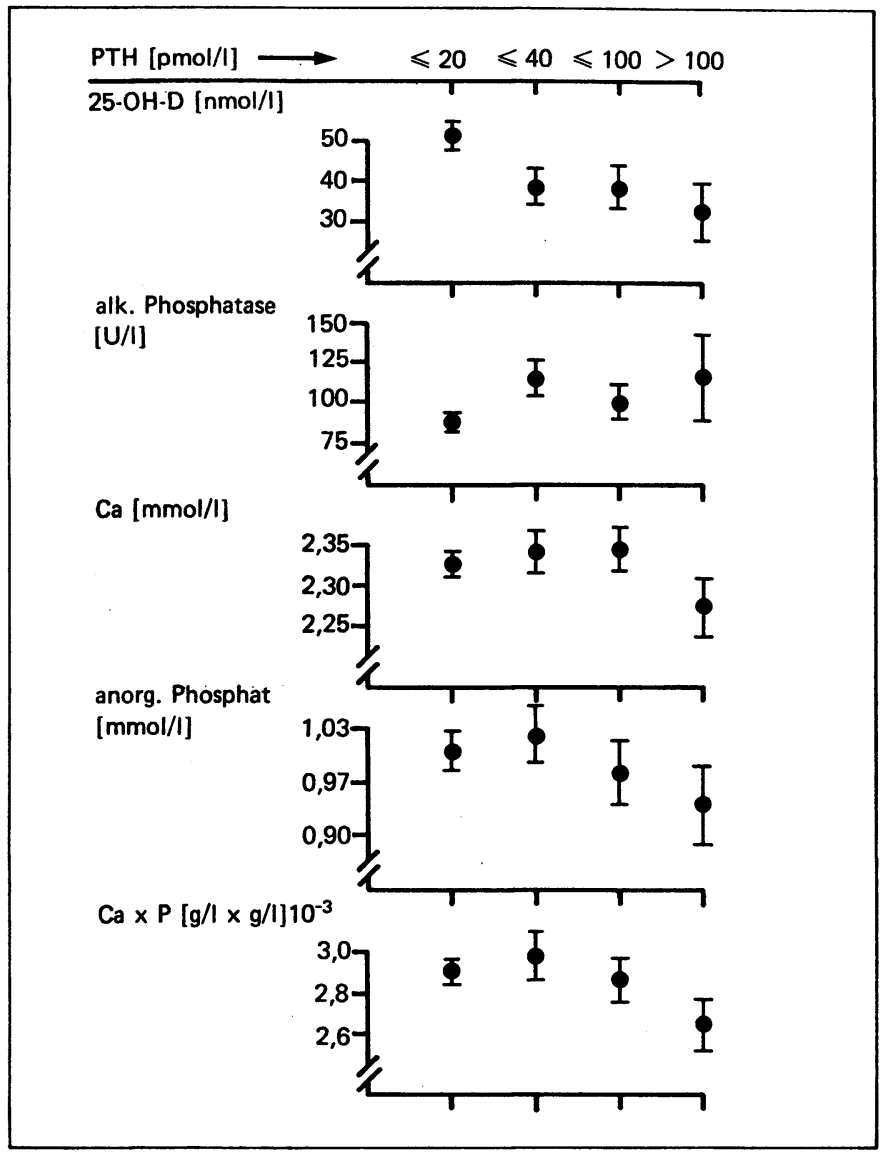

Abb. 6. Beziehung zwischen Parathormon (PTH) im Serum (4 Stufen: $\leq 20[n=49],>20-\leq 40[n=25],>40-\leq 100[n=17]$, $>100[\mathrm{n}=9] \mathrm{pmol} / \mathrm{l}$ ) und den übrigen Serumwerten (jeweils $\overline{\mathrm{x}} \pm \mathrm{s})$.

gesehen. Erniedrigungen des 25-HydroxycholecalciferolSpiegels sind somit als ein besonders empfindliches Kriterium zu werten. Dabei ist allerdings eine gewisse Inkonstanz bei der Bestimmung der 25-Hydroxycholecalciferol-Werte zu bedenken, die deutlich abhängig sind von äußeren Einflüssen wie Nahrung und Jahreszeit. Die Untersuchungen wurden überwiegend in den Sommermonaten durchgeführt; bei unseren gesunden Probanden stieg der 25-Hydroxycholecalciferol-Spiegel in dieser Zeit im Vergleich mit den übrigen Jahreszeiten, in denen sich ein unterer Grenzwert von $25 \mathrm{nmol} / \mathrm{l}$ ergeben hatte, an. Wir legten trotzdem diesen Wert als unteren Normalwert fest, da nach eigenen Untersuchungen bei nutritivem oder durch Mangel an UV-Strahlung bedingtem Vitamin-D-Mangel das Serum-Calcium erst bei einem 25-Hydroxycholecalciferol-Spiegel unter $25 \mathrm{nmol} / \mathrm{l}$ absinkt und im Sommer gemessene 25-Hydroxycholecalciferol-Spiegel zwischen 25 und $50 \mathrm{nmol} / 1$ somit allenfalls für einen relativen Vitamin-D-Mangel sprächen. Die von uns gefundene Erniedrigung des 25Hydroxycholecalciferol-Spiegels in $23 \%$ der Fälle entspricht im wesentlichen der Angabe von 33\% in der Literatur (11), die allerdings an einer erheblich geringeren Patientenzahl gewonnen wurde. Eine deutliche Erniedrigung des 25-Hydroxycholecalciferol-Spiegels im Vergleich zu einer Gruppe gesunder Personen fanden auch Stamp und Mitarbeiter (21) bei elf Epileptikern. Auf die ausgezeichnete Korrelation zu unseren Röntgenbefunden sowie auf die recht gute Korrelation zu den Werten der alkalischen Phosphatase und des Calciums wurde bereits hingewiesen. Auch die Tatsache, daß von allen Serumwerten die 25-Hydroxycholecalciferol-Spiegel-Erniedrigung am häufigsten mit zwei und mehr pathologisch veränderten Parametern kombiniert war, spricht für den hohen diagnostischen Wert dieser Bestimmung zur Aufdeckung der Osteopathien.

Röntgenveränderungen. Direkt am Skelettsystem nachweisbare Auffälligkeiten waren mit 39\% der häufigste bei unseren Kranken erhobene pathologische Befund. Dies war auch bei der methodisch allerdings unterschiedlichen Untersuchung von Sotaniemi und Mitarbeitern (20) der Fall, die mit $77 \%$ einen noch beträchtlich höheren Anteil pathologischer Befunde hatten. Selbst bei unserem niedrigeren Wert von $39 \%$ positiver Befunde wiesen einige der betroffenen Patienten zur Zeit der Untersuchung nach den übrigen Parametern noch keinen sicheren Anhalt für eine Osteomalazie auf; hier sind eingehende Verlaufskontrollen erforderlich. Bei der langen Anlaufs- wie auch Erholungszeit beim Nachweis osteomalazischer Veränderungen im Röntgenbild könnten durchaus Fälle mit latenter Osteopathie miterfaßt sein, die aufgrund vermehrter Vitamin-D-Zufuhr (Nahrung, UV-Strahlung) hinsichtlich der serologischen Parameter zum Zeitpunkt der Untersuchung weitgehend normalisiert waren. $\mathrm{Zu}$ bedenken ist ferner, daß röntgenologisch häufig keine reinen Ja-Nein-Antworten gegeben werden können, so daß letztlich auch fraglich positive Befunde miterfaßt werden. Daß prinzipiell ein hoher Prozentsatz pathologischer Befunde am Skelettsystem erwartet werden darf, zeigten die bisher durchgeführten densitometrischen Untersuchungen, in denen bei den antiepileptisch behandelten Patienten signifikante Erniedrigungen der Knochendichte bei Photonenabsorptionsmessungen nachgewiesen wurden $(4,14)$. Hervorzuheben ist bei unseren Fällen die ausgezeichnete Korrelation der Röntgenbefunde mit erniedrigten 25-HydroxycholecalciferolSpiegeln. Deutlich schlechter war die Korrelation zwischen den Röntgenbefunden, insbesondere der Stufe 2, und den Werten der alkalischen Phosphatase; dies wird in der Literatur bestätigt (20). Ähnlich war auch die Beziehung zwischen Röntgenbefunden und Calciumspiegeln, wobei auffiel, daß bei verdächtigen Röntgenbefunden der Stufe 2 die Calciumwerte zwar signifikant niedriger lagen als bei Stufe 1, sich jedoch häufig noch im Normalbereich bewegten.

Übrige Serumwerte. Die von uns gefundene Häufigkeit einer Aktivitätserhöhung der alkalischen Phosphatase in $20 \%$ liegt zwischen den von Wright (23) mit $18 \%$ und den von Richens und Rowe (16) mit $29 \%$ sowie von Sotaniemi und Mitarbeitern (20) mit 30\% gefundenen Werten; in anderen Arbeiten wurden aber erheblich höhere Prozentsätze von 61 bzw. 76,5 $(7,8,14)$ beschrieben. Auf die relativ schwache Korrelation zu den Verdachtsfällen bei der Röntgenuntersuchung wurde bereits hingewiesen. Gut war die Beziehung zum 25Hydroxycholecalciferol-Spiegel. Festzuhalten ist, daß in einem Fall mit röntgenologisch und bioptisch gesicherter Osteopathie die alkalische Phosphatase mit $70 \mathrm{U} / 1$ eindeutig im Normbereich lag. 
Eine Bestimmung des Parathormons wurde bisher nur in einem Einzelfall bei einem an einer schweren Osteopathia antiepileptica erkrankten erwachsenen Patienten durchgeführt, wobei erwartungsgemäß ein sekundärer Hyperparathyreoidismus nachgewiesen werden konnte (10). Auf die Korrelation der bei uns mit $26 \%$ recht häufig erhöhten Parathormon-Werte wurde bereits eingegangen.

Besonders bemerkenswert erscheint, daß ein Absinken des Calciums auf durchschnittliche Werte um 2,25 mmol/1 erst bei einem schon sehr ausgeprägten sekundären Hyperparathyreoidismus zu konstatieren war. Unser Gesamtwert von $24 \%$ erniedrigter Serum-Calciumwerte entspricht den Literaturangaben von $6-30 \%(7,11,16$, 20). Die Korrelation zu den anderen Befunden war, wie schon ausgeführt, teilweise recht gut, allerdings bestand bei einem Viertel der erniedrigten Calciumspiegel keine Kombination mit einem weiteren pathologischen Wert.

Die Häufigkeit von $17 \%$ erniedrigter Werte beim anorganischen Phosphat deckt sich weitgehend mit der Angabe von Sotaniemi und Mitarbeitern (20) von $14 \%$. Wie Richens und Rowe (16) fanden wir beim anorganischen Phosphat keine überzeugende Korrelation mit den übrigen Parametern. Eine wesentliche Bedeutung bei der Diagnostik der Osteopathia antiepileptica scheint dem anorganischen Phosphat nach unseren Befunden ebensowenig zuzukommen wie dem Calcium-Phosphat-Produkt.

\section{Folgerungen für die Praxis}

Trotz der Häufigkeit der bei Langzeitmedikation von Antiepileptika auftretenden Knochenstoffwechselstörungen mit entsprechenden pathologischen Röntgenbefunden und Serumwerten konnte man sich bisher nicht dazu entschließen, in jedem Falle einer antiepileptischen Langzeitbehandlung die prophylaktische Gabe von Vitamin D zu empfehlen. Die Bestimmung der alkalischen Phosphatase als alleiniger Suchtest für beginnende Osteopathien, wie er von manchen Autoren angeregt wurde, die ihre Erfahrungen vorwiegend an Kindern und Jugendlichen gewonnen hatten, ist nach unseren Ergebnissen bei Erwachsenen nicht ausreichend. Es erscheint danach angebracht, nach Möglichkeit bei solchen Patienten einmal pro Jahr neben den Routinebestimmungen von Serumwerten wie alkalischer Phosphatase und Calcium Röntgenuntersuchungen des Skeletts und Bestimmungen des 25-Hydroxycholecalciferol-Spiegels durchzuführen. Bei der Erstuntersuchung von langzeitig antiepileptisch behandelten Patienten sollten Becken, Lendenwirbelsäule sowie Hände und Füße geröntgt werden; in den Folgejahren scheinen dann nach unseren Erfahrungen Aufnahmen der Hände in Mammographietechnik, die mit einer nur geringen Gonadenbelastung verbunden sind, zur Früherkennung osteomalazischer Veränderungen ausreichend zu sein. Die Bestimmung des 25-Hydroxycholecalciferol-Spiegels erforderte bisher noch einen sehr großen technischen Aufwand, sie wird aber in Zukunft in vielen Laboratorien durchführbar sein, seitdem jetzt Nachweismethoden ohne vorherige Chromatographie entwickelt wurden (3). Unsere Empfehlungen stützen sich darauf, daß bei den untersuchten

Patienten die Röntgenbefunde deutlich besser mit den 25-Hydroxycholecalciferol-Werten als mit denen der alkalischen Phosphatase und des Calciums korrelierten. Bei mehreren Patienten, die röntgenologisch auffällig waren und auch erniedrigte 25-HydroxycholecalciferolSpiegel aufwiesen, lag der Wert der alkalischen Phosphatase noch im Normbereich. Bei dem erwähnten $\mathrm{Pa}$ tienten mit bioptisch gesicherter Osteopathie bei pathologischen Röntgenaufnahmen und erniedrigtem 25Hydroxycholecalciferol-Spiegel wäre keine prophylaktische Gabe von Vitamin D erfolgt, wenn man nur die Bestimmung der alkalischen Phosphatase als Screening-Test benutzt hätte; die Verabreichung von VitaminD-Präparaten ist aber, wenn sie schon nicht generell durchgeführt wird, wenigstens in solchen Fällen unbedingt zu fordern.

Als Kriterien für eine prophylaktische Gabe von niedrigen Tagesdosen eines Vitamin-D-Präparates (1000 IE oral $^{1}$ ) sollten unseres Erachtens somit Auffälligkeiten im Röntgenbild oder leicht erniedrigte 25 -Hydroxycholecalciferol-Spiegel gelten. Die Indikation zu einer höherdosierten Therapie besteht, wenn schwere röntgenologische Veränderungen entweder allein oder in Kombination mit pathologischen Serumwerten vorliegen, aber auch dann, wenn nur stark erniedrigte 25 -Hydroxycholecalciferol-Spiegel nachgewiesen werden. In diesen Fällen sollte zunächst eine dreimonatige orale Verabreichung von 10000 IE Vitamin D pro Tag erfolgen, danach wäre auf eine Erhaltungsdosis von $1000 \mathrm{IE} / \mathrm{d}$ überzugehen.

Die von uns zur Aufdeckung eines sekundären Hyperparathyreoidismus zusätzlich durchgeführten Parathormon-Bestimmungen sind methodisch aufwendig; sie geben nach unseren Erfahrungen außerdem keine so wesentliche Information im Vergleich mit den anderen Untersuchungsmethoden, daß ihre Verwendung als Routineverfahren notwendig erscheint.

\footnotetext{
${ }^{1}$ Die Verabreichung von 1000 IE Vitamin D pro Tag ist gefahrlos. Wir beobachteten bei Gesunden im Winter unter dem Einfluß dieser Dosis nur einen Anstieg des 25-Hydroxycholecalciferol-Spiegels um durchschnittlich $40 \mathrm{nmol} / \mathrm{l}$ von 30 auf $70 \mathrm{nmol} / \mathrm{l}$.
}

\section{Literatur}

(1) Arnaud, C. D., H. S. Tsao, T Littledike: Radioimmunoassay of human parathyroid hormone in serum. J. clin. Invest. 50 (1971), 21. (2) Barwich, D.: Myopathie und Osteomalazie nach langdauernder antiepileptischer Behandlung. Münch. med. Wschr. 116 (1974), 2113.

(3) Belsey, R. E., H. F. DeLuca, J. T. Potts jr.: A rapid assay for 25-OH-vitamin $\mathrm{D}_{3}$ without preparation chromatography. J. clin. Endocr. 38 (1974), 1046

(4) Christiansen, C., P. Rodbro, M. Lund: Effect of vitamin $D$ on bone mineral mass in normal subjects in epileptic patients on anticonvulsants. A controlled therapeutic trial. Brit. med. J. 1973/2, 208.

(5) Dent, C. E., A. Richens, D. J. F. Rowe, T. C. B. Stamp: Osteomalacia with long-term anticonvulsant therapy in epilepsy. Brit. med. J. 1970/4, 69. (6) Edelstein, S., M. Charman, D. E. M Lawson, E. Kodicek: Competitive protein-binding assay for 25 -hydroxy- cholecalciferol. Clin. Sci. 46 (1974), 231.

(7) Flury, W. H.: Osteomalazie nach langdauernder antiepileptischer Behandlung. Schweiz. med. Wschr. 102 (1972), 1333.

(8) Funck, E.: Bestimmung der alkalischen Serumphosphatase als Suchtest nach Osteopathien bei antiepileptischer Langzeittherapie. Dissertation, Heidelberg 1972.

(9) Garn, S. M.: The earlier gain and the later loss of cortical bone. In: Nutritional Perspective (C. C. Thomas: Springfield/lll. 1970).

(10) Genuth, S. M., L. Klein, S.

Rabinovich, K. C. King: Osteomalacia accompanying chronic anticonvulsant therapy. J. clin. Endocr. 35 (1972), 378.

(11) Hahn, T. J., B. A. Hendin, C. R. Scharp, J. G. Haddad: Effect of chronic anticonvulsant therapy on serum 25-hydroxy-cholecalciferol levels in adults. New Engl. J. Med. 287 (1972), 900.

(12) Kraft, D., K. Schaefer, W. Bochentin, D. von Herrath, A. Opitz, 
P. Koeppe: Untersuchungen zum Calcium-Stoffwechsel bei antiepileptischer Therapie. Nervenarzt 44 (1973), 150.

(13) Kruse, R.: Osteopathien bei antiepileptischer Langzeittherapie. Mschr. Kinderheilk. 116 (1968), 378.

(14) Kruse, R.: Osteopathien, Kalziumund Vitamin-D-Stoffwechselstörungen unter antiepileptischer Langzeittherapie. In: Antiepileptische Langzeitmedikation.

Bibl. psychiat. (Basel) 151 (1975).

(15) Linde, J., J. M. Hansen, K. Siersback-Nielsen, V. Fuglsang-

Fredriksen: Bone density in patients

receiving long-term anticonvulsant therapy. Acta neurol. scand. 47 (1971), 650.

(16) Richens, A., D. J. F. Rowe:

Disturbance of calcium metabolism by anticonvulsant drugs. Brit. med. J. 1970/4, 73.

(17) Richens, A., D. J. F. Rowe:

Anticonvulsant osteomalacia. Brit. med.

J. 1971/4, 684

(18) Ritter, G., W. F. Caspary, R. D.

Hesch, R. Matte, D. Emrich: Therapie der Kalziumresorptionsstörung unter antiepileptischer Behandlung mit 25-Hydroxycholekalziferol (25-HCC) In: Antiepileptische Langzeitmedikation. Bibl. psychiat. (Basel) 151 (1975) (19) Schmid, F.: Osteopathien bei antiepileptischer Dauerbehandlung. Fortschr. Med. 85 (1967), 381.

(20) Sotaniemi, E. A., H. K. Kakkarainen, J. A. Puranen, R. O. Lahti: Radiologic bone changes and hypocalcaemia with anticonvulsant therapy. Ann. intern. Med. 77 (1972), 389.
(21) Stamp, C. B., J. M. Round, D. J. F. Rowe, J. G. Haddad: Plasma levels and therapeutic effect of

Bhaktaviziam, G. M. Taori: Osteomalacia due to phenytoin sodium. J. neurol. Sci. 19 (1973), 287.

25 -hydroxycholecalciferol in epileptic patients taking anticonvulsant drugs. Brit. med. J. 1972/4, 9.

(22) Varkey, K., P. T. Raman, A.

(23) Wright, J. A.: Trinuride in the treatment of major epilepsy. Epilepsia (Amst.) 6 (1965), 67.

\section{Dr. K.-H. Krause}

Neurologische Universitätsklinik 6900 Heidelberg, Voßstr. 2

Dr. P. Prager

Universitäts-Strahlenklinik 6900 Heidelberg, Voßstr. 3

Dr. H. Schmidt-Gayk, Prof. Dr. E. Ritz

Medizinische Universitätsklinik

6900 Heidelberg, Bergheimer Str. 58 